\title{
Polarimetric Radar Relations for Quantification of Snow Based on Disdrometer Data
}

\author{
PetAR BukovČIĆ \\ NOAA/National Severe Storms Laboratory, and Cooperative Institute for Mesoscale Meteorological Studies, and \\ School of Meteorology, and Advanced Radar Research Center, University of Oklahoma, Norman, Oklahoma
}

ALEXANDER RYZHKOV

Cooperative Institute for Mesoscale Meteorological Studies, University of Oklahoma, Norman, Oklahoma

DUSAN ZRNIĆ

NOAA/National Severe Storms Laboratory, Norman, Oklahoma

GUIFU ZHANG

School of Meteorology, and Advanced Radar Research Center, University of Oklahoma, Norman, Oklahoma

(Manuscript received 4 April 2017, in final form 15 September 2017)

\begin{abstract}
Accurate measurements of snow amounts by radar are very difficult to achieve. The inherent uncertainty in radar snow estimates that are based on the radar reflectivity factor $Z$ is caused by the variability of snow particle size distributions and snow particle density as well as the large diversity among snow growth habits. In this study, a novel method for snow quantification that is based on the joint use of radar reflectivity $Z$ and specific differential phase $K_{\mathrm{DP}}$ is introduced. An extensive dataset of 2D-video-disdrometer measurements of snow in central Oklahoma is used to derive polarimetric relations for liquid-equivalent snowfall rate $S$ and ice water content IWC in the forms of bivariate power-law relations $S=\gamma_{1} K_{\mathrm{DP}}^{\alpha_{1}} Z^{\beta_{1}}$ and IWC $=\gamma_{2} K_{\mathrm{DP}}^{\alpha_{2}} Z^{\beta_{2}}$, along with similar relations for the intercept $N_{0 \mathrm{~s}}$ and slope $\Lambda_{s}$ of the exponential snow size distribution. The physical basis of these relations is explained. Their multipliers are sensitive to variations in the width of the canting angle distribution and to a lesser extent the particles' aspect ratios and densities, whereas the exponents are practically invariant. This novel approach is tested against the $S(Z)$ relation using snow disdrometer measurements in three geographical regions (Oklahoma, Colorado, and Canada). Significant improvement in snow estimates relative to the traditional $Z$-based methods is demonstrated.
\end{abstract}

\section{Introduction}

Radar measurements of snow are challenging because of the tremendous variability among snow particle size distributions (PSDs), density, water content, shape, orientation, crystal habits, etc. Thus, radar quantitative precipitation estimation (QPE) of snow is very difficult (Mitchell et al. 1990).

There have been many radar-based studies on the estimation of snowfall rates in the past half century. The vast majority of these studies utilize power-law relations between the equivalent radar reflectivity $\left(Z_{e}\right.$, herein $\left.Z\right)$ and liquid water equivalent snowfall rate $(S$, also LWE),

Corresponding author: Petar Bukovčić, petar.bukovcic@ou.edu
$Z=a S^{b}$ (e.g., Gunn and Marshall 1958; Ohtake and Henmi 1970; Sekhon and Srivastava 1970; Puhakka 1975; Fujiyoshi et al. 1990; Koistinen et al. 2003; Matrosov 2007; Matrosov et al. 2009; Huang et al. 2010; Szyrmer and Zawadzki 2010; Zhang et al. 2011; Wolfe and Snider 2012; Heymsfield et al. 2016). Most of these relations assume that $Z$ is proportional to $S^{2}$. The multitude of power-law $Z-S$ relations (some of which are presented in Table 1 and Fig. 1) exhibit roughly an order of magnitude difference in the estimates of snowfall rate for the same reflectivity factor $Z$. None of the previous studies have capitalized on the emergence of polarimetric radar capabilities for the estimation of $S$.

Ice water content (IWC) is another important microphysical parameter characterizing glaciated parts of 
TABLE 1. Summary of $Z(S)$ relations for dry snow listed in the literature and utilized by the WSR-88D network in the United States.

\begin{tabular}{ll}
\hline \hline \multicolumn{1}{c}{ Source } & \multicolumn{1}{c}{$\begin{array}{c}Z(S) \text { relation } \\
\text { for dry snow }\end{array}$} \\
\hline Gunn and Marshall (1958) & $Z=448 S^{2}$ \\
Sekhon and Srivastava (1970) & $Z=399 S^{2.21}$ \\
Ohtake and Henmi (1970) & $Z=739 S^{1.7}$ \\
Puhakka (1975) & $Z=235 S^{2}$ \\
Koistinen et al. (2003) & $Z=400 S^{2}$ \\
Huang et al. (2010) & $Z=(106-305) S^{(1.11-1.92)}$ \\
Szyrmer and Zawadzki (2010) & $Z=494 S^{1.44}$ \\
Wolfe and Snider (2012) & $Z=110 S^{2}$ \\
WSR-88D, Northeast & $Z=120 S^{2}$ \\
WSR-88D, north plains-upper & $Z=180 S^{2}$ \\
$\quad$ Midwest & $Z=130 S^{2}$ \\
WSR-88D, high plains & $Z=40 S^{2}$ \\
WSR-88D, Intermountain West & $Z=222 S^{2}$ \\
WSR-88D, Sierra Nevada &
\end{tabular}

clouds. There have been a number of studies in which the IWC of clouds is estimated using the radar reflectivity factor $Z$ in the form of IWC $=c Z^{d}$ (e.g., Sekhon and Srivastava 1970; Heymsfield 1977; Sassen 1987; Atlas et al. 1995; Liu and Illingworth 2000; Hogan et al. 2006; Delanoë et al. 2014; Heymsfield et al. 2016).

The common thread in all of these studies is the large variability of $Z$-IWC relations in space (i.e., from cloud to cloud) and time (Ryzhkov et al. 1998). Adequate representation of IWC in numerical weather prediction (NWP) models is needed to improve quantitative precipitation forecasts (QPFs), as well as global circulation and climate models, because ice clouds strongly affect the earth's radiation balance (Stephens et al. 1990). This magnifies the importance of measuring the IWC in situ or remotely so that comparisons with model estimates can be made.

A few studies that explored polarimetric methods for IWC estimation are examined next. Vivekanandan et al. (1994) advocate use of a specific differential phase, $K_{\mathrm{DP}}$, for IWC estimation. Aydin and Tang (1995) combine $K_{\mathrm{DP}}$ and the differential reflectivity $Z_{\mathrm{DR}}$ for IWC estimation in clouds composed of pristine ice crystals assuming that the density of the crystals is equivalent to the density of solid ice. Ryzhkov et al. (1998) propose IWC estimation for pristine ice crystals (or lightly to moderately aggregated crystals) from a combination of $K_{\mathrm{DP}}$ and reflectivity difference $Z_{\mathrm{DP}}$ or $K_{\mathrm{DP}}$ alone.

We use extensive snow disdrometer data-measured snow PSDs, collected in central Oklahoma from late 2006 until early 2015-to derive polarimetric relations for liquid water equivalent snow rate $S$ and ice water content IWC. Similarly, relations for intercept $N_{0 \mathrm{~s}}$ and slope $\Lambda_{s}$ of an exponential size distribution are also

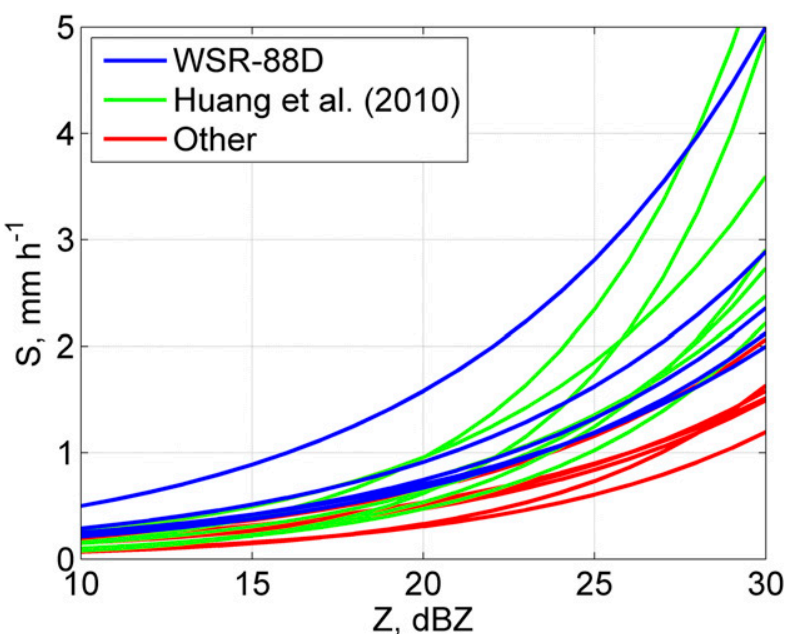

FIG. 1. Summary of $Z(S)$ relations for dry snow listed in the literature and utilized by the WSR-88D network in the United States.

derived from snow PSD measurements. For these relations, we choose a power-law form $V=\gamma K_{\mathrm{DP}}^{\alpha} Z^{\beta}$, where $V$ represents any of the variables/parameters: $S$, IWC, $N_{0 \mathrm{~s}}$, or $\Lambda_{s}$. Our proposed methodology is applicable to the cloud depth from the ice crystal forming region through aggregation, which in winter storms can often extend down to the ground. We submit that over such layer the flux of ice water is constant. In such cases, the $K_{\mathrm{DP}}$ would decrease from the top down, whereas $Z$ would increase. Therefore, a single relation using either of these two variables would miss the total amount. The combined relation compensates for these two opposing trends and more accurately quantifies the constant snow flux throughout the cloud depth.

The paper is organized as follows. Section 2 contains a description of the acquisition and processing of snow disdrometer data. A methodology for the computation of snow microphysical parameters $S$ and IWC, and polarimetric variables $Z$ and $K_{\mathrm{DP}}$, is presented in section 3 , whereas a theoretical background for $Z-S$ and $Z$-IWC parameterization is discussed in section 4 . The results from the 2D-video-disdrometer (2DVD) estimated $S(2 \mathrm{DVD})$ and IWC(2DVD) and expected $S$ and IWC results from disdrometer data $\left[S(Z), S\left(K_{\mathrm{DP}}\right), S\right.$ $\left(K_{\mathrm{DP}}, Z\right), \operatorname{IWC}(Z), \operatorname{IWC}\left(K_{\mathrm{DP}}\right)$, and $\left.\operatorname{IWC}\left(K_{\mathrm{DP}}, Z\right)\right]$ are included in section 5 , followed by a discussion and summary in sections 6 and 7 .

\section{Datasets and 2DVD processing}

\section{a. Datasets}

The 2DVD observations of snow in central Oklahoma were made during the period from November 2006 until March 2015. The disdrometer was deployed at Kessler 
Atmospheric and Ecological Field Station (KAEFS), the University of Oklahoma (OU) test site approximately $15 \mathrm{~km}$ west of Purcell, Oklahoma, at $\sim 350 \mathrm{~m}$ above sea level. Sixteen snow events were observed and a total of $\sim 7000$ one-minute snow particle size distributions were sampled. Using the measurements of temperature and humidity, most of the precipitation was classified as dry aggregated snow; the thermodynamic vertical profiles retrieved from the Rapid Update Cycle (RUC) or Rapid Refresh (RAP) models aided this classification. Episodes of mixed-phase precipitation were excluded from the dataset.

For 9 out of 16 snow events, snow water equivalent (SWE) amounts were recorded at a nearby Oklahoma Mesonet (Washington) station; measurements were of total melted SWE amounts from a regular rain gauge (about $400 \mathrm{~m}$ away from the 2DVD). Since the acquisition of a heated rain gauge (2013), we have compared the amounts with the Washington station (after melting) and found relatively good agreement. This gave us confidence in the total snow water amounts collected previously.

Until 2014, there was no wind measurement directly at the Oklahoma 2DVD site, but only observation made $400 \mathrm{~m}$ away on the hill. After the wind sensor installation at the 2DVD site, the measurements between these two locations indicate an average difference of about $1-4 \mathrm{~m} \mathrm{~s}^{-1}$ (median is $\sim 3 \mathrm{~m} \mathrm{~s}^{-1}$ ), with higher winds at the top of the hill. Application of this correlation to all Oklahoma snow events revealed only a few short periods with winds above $4 \mathrm{~m} \mathrm{~s}^{-1}$ during 4 of 16 events. We excluded these from the analysis but used them for the estimation of the total SWE amounts. The rest of the events (including Colorado and Canada 2DVD measurements) had ambient wind speeds of less than $4 \mathrm{~m} \mathrm{~s}^{-1}$.

\section{b. 2DVD processing}

The 2D video disdrometer (Kruger and Krajewski 2002; Schönhuber et al. 2008) is an optical instrument that directly measures the particles' size, shape, and terminal velocity, allowing for the construction of PSDs. The horizontal resolution of the 2DVD measurements is approximately $0.2 \mathrm{~mm}$ while the vertical resolution depends on the hydrometeors' terminal velocities and ranges from 0.1 to $0.2 \mathrm{~mm}$. The particles are partitioned into 101 size bins, each $0.2 \mathrm{~mm}$ wide and centered at diameters ranging from 0.1 to $20.1 \mathrm{~mm}$.

The instrument has two line-scan cameras placed orthogonally, with planes of view separated by about $6.2-7.0 \mathrm{~mm}$ and illuminated by two light sources. The device was originally designed for raindrop size distribution and shape measurements. As a raindrop falls through the virtual measurement area, line cameras record two orthogonal views, so that it is fairly straightforward to match images and construct a 2D view of the drop. Because of the $6.2-7.0-\mathrm{mm}$ vertical displacement between the cameras, it is possible to measure a raindrop's fall speed. Whereas it is rather easy to match two raindrop images because of their high symmetry with respect to the minor axis, it has been demonstrated that 2DVD snow data processing using manufacturer's proprietary software is problematic (Hanesch 1999; Huang et al. 2010, 2015).

A large amount of mismatching occurs in the case of snow because the snow particles' diverse shapes produce dissimilar orthogonal images. Only the vertical dimensions of the particles (measured in a number of line scans) from two orthogonal cameras are suitable for matching. According to the manufacturer's matching software, the particle is considered matched if the vertical dimensions from the two orthogonal images are within certain tolerances. That way, the first two particles that pass the criteria are matched. A better matching procedure described by Huang et al. (2010) examines all possible pairs within a prescribed time window. Our attempt to use this matching criterion produced slightly higher particle fall speeds than expected. After the refinements, reflected in adding another membership function that utilized the ratio of measured versus empirical velocity, fall speeds agreed slightly better with the expected results. Thus, this approach was abandoned. Instead, we made adjustments to the original matching algorithm as follows.

We have applied an additional filter to the originally matched particles: the height ratio of the orthogonal images (denoted as $f_{1}$ ) and the ratio of the measured terminal velocity $V_{m}$ to the empirically predetermined value $V_{e}$ (denoted as $f_{2}$ ). These ratios are forced to be less than or equal to 1 :

$$
\begin{aligned}
f_{1} & =H_{A} / H_{B} \quad \text { if } \quad H_{A} \leq H_{B} \quad \text { or } \\
f_{1} & =H_{B} / H_{A} \text { otherwise, and } \\
f_{2} & =V_{m} / V_{e} \text { if } \\
V_{m} & \leq V_{e} \text { or } f_{2}=V_{e} / V_{m} \quad \text { otherwise. }
\end{aligned}
$$

In (1) and (2), $H_{A}$ and $H_{B}$ are the particle's heights measured by orthogonal cameras and $V_{e}$ is the empirical terminal velocity specified by Brandes et al. (2007; see section 3). Finally, the product $f_{1} f_{2}$ is used as an adaptable threshold that depends on the measured amount of SWE by a reference gauge. The values typically range between 0.5 and 0.65 . In this way, the original 2DVD matching with all available statistics becomes usable and physically realistic. 
The total SWE amounts are determined from Oklahoma Mesonet (Washington) rain gauge measurements. The data are filtered in the way described above, where the mean threshold is derived from the available SWE estimates. Additionally, because of the problem with our unit's camera focus for particles smaller than $\sim 0.7 \mathrm{~mm}$, extrapolation from the 1-min measured distribution size range of $1-4 \mathrm{~mm}$ (if a total number of particles within this size range is equal to or larger than 6) is used to quantify PSDs at particle sizes less than $1 \mathrm{~mm}$. For the distributions where the number of particles is less than 6 within the prescribed size range, measured distributions are accepted as is.

\section{Methodology}

The snow water equivalent rate $S$ (expressed in $\mathrm{mm} \mathrm{h}^{-1}$ ) is computed as

$$
S=\frac{\pi}{6 \Delta t} \sum_{i=1}^{L} \frac{\rho_{s}\left(D_{i}\right)}{\rho_{w}} \frac{C\left(D_{i}\right) D_{i}^{3}}{A\left(D_{i}\right)} .
$$

The term $\Delta t$ is the summation time period in hours, $C\left(D_{\mathrm{i}}\right)$ represents the number of particles collected during the time period in the $i$ th size bin, $A\left(D_{\mathrm{i}}\right)$ is the mean 2DVD effective area $\left(\mathrm{mm}^{2}\right)$ for the $i$ th size bin, $D_{i}$ is the equivolume diameter representing the bin center $(\mathrm{mm})$, and $\rho_{w}$ and $\rho_{s}$ are the densities of water and snow $\left(\mathrm{g} \mathrm{cm}^{-3}\right)$. For the 1-min summation period, (3) simplifies to

$$
S=10 \pi \sum_{i=1}^{L} \frac{\rho_{s}\left(D_{i}\right)}{\rho_{w}} \frac{C\left(D_{i}\right) D_{i}^{3}}{A\left(D_{i}\right)} .
$$

The IWC $\left(\mathrm{g} \mathrm{m}^{-3}\right)$ is calculated via

$$
\mathrm{IWC}=\frac{\pi}{6} 10^{-3} \sum_{i=1}^{L} \rho_{s}\left(D_{i}\right) D_{i}^{3} N\left(D_{i}\right) \Delta D,
$$

where $N\left(D_{i}\right)$ is the measured particle size distribution (in $\mathrm{m}^{-3} \mathrm{~mm}^{-1}$ ).

There are multiple density-size relations in the literature (e.g., Brown and Francis 1995; Matrosov 1997; Brandes et al. 2007; Szyrmer and Zawadzki 2010; Tiira et al. 2016). These are usually between the mean snow density $\left\langle\rho_{s}\right\rangle$ determined as a ratio of the total mass to total volume of snow in the whole size distribution and the median volume diameter $D_{0}$. For example, the relation from Brandes et al. (2007) is

$$
\left\langle\rho_{s}\right\rangle=0.178 D_{0}^{-0.922} .
$$

It can be shown that for exponential size distribution the dependence $\rho_{\mathrm{s}}(D)$, where $D(\mathrm{~mm})$ is the particle equivalent volume diameter, has the same exponent as the $\left\langle\rho_{s}\left(D_{0}\right)\right\rangle$ relation but with a slightly different multiplier (about $18 \%$ smaller). Most of the density relations cited in the literature have the exponent close to -1 , but the multiplier can vary significantly. Matrosov (1997) claims that the multiplier is higher for ice particles observed at higher altitudes (using in situ aircraft measurements) than for particles observed near the surface (from ground measurements). The multiplier of the power-law densitysize relationship is higher for rimed snow. Zawadzki et al. (2005) use the degree of riming factor, $f_{\text {rim }}$, to account for riming of different intensities so that

$$
\rho_{s}(D)=c_{\rho} f_{\text {rim }} D^{-\delta}
$$

and $f_{\text {rim }}=1$ for unrimed snow. Zhang et al. (2011) and Zhang (2016) recommend using the measured ratio $V_{m}$ $(D) / V_{e}(D)$ to account for the change of the multiplier and the variable degree of riming across the snow spectrum. Here, we follow the suggestion of Zhang et al. (2011) and Zhang (2016) to estimate the degree of riming $f_{\text {rim }}$ as

$$
f_{\text {rim }}(D)=\left[\frac{V_{m}(D)}{V_{e}(D)}\right]^{2},
$$

where

$$
V_{e}(D)=0.768 D^{0.142}
$$

is the relation obtained by Brandes et al. (2007) in Colorado (Marshall, National Center for Atmospheric Research Snowfall Test Site at the height of $1742 \mathrm{~m}$ MSL). The velocity ratio in (7) could be regarded as a proxy for riming because the increase in the ratio of $V_{m} / V_{e}$ increases the degree of rimming. Because of the dependence of the terminal velocity on the air density, $V_{m}(D)$ in (7) should be adjusted to the air density at which (7) is valid. This is done by multiplying $V_{m}$ with the square root of the ratio $\rho_{a}(O) / \rho_{a}(C)$, where $\rho_{a}(O)$ is the air density at the observational site and $\rho_{a}(C)$ is the standard air density at $h=1742 \mathrm{~m}$ MSL.

The intercept $N_{0 \mathrm{~s}}\left(\mathrm{~m}^{-3} \mathrm{~mm}^{-1}\right)$ and slope $\Lambda_{s}\left(\mathrm{~mm}^{-1}\right)$ of the exponential size distribution are determined from the 2DVD-measured snow size distributions using the second and fourth PSD moments. The $n$th moment of the PSD, where the second equality is valid only for the exponential PSD model, is defined as

$$
M_{n}=\int_{0}^{\infty} D^{n} N(D) d D=N_{0 \mathrm{~s}} \Lambda_{s}^{-(n+1)} \Gamma(n+1) .
$$

Hence, the parameters $\Lambda_{s}$ and $N_{0 \mathrm{~s}}$ can be computed as

$$
\Lambda_{s}=\left(12 M_{2} / M_{4}\right)^{1 / 2}
$$


and

$$
N_{0 \mathrm{~s}}=\frac{M_{2} \Lambda_{s}^{3}}{2}
$$

The polarimetric variables are computed from 2DVD measurements as follows (Ryzhkov et al. 2011):

$$
Z=\frac{4 \lambda^{4}}{\pi^{4}\left|K_{w}\right|^{2}} \int_{0}^{\infty}\left\langle\left|s_{a}{ }^{(\pi)}\right|^{2}-2 \operatorname{Re}\left\{s_{a}{ }^{(\pi)^{*}}\left[s_{a}{ }^{(\pi)}-s_{b}{ }^{(\pi)}\right]\right\} A_{2}+\left|s_{a}^{(\pi)}-s_{b}^{(\pi)}\right|^{2} A_{4}\right\rangle N(D) d D
$$

$$
K_{\mathrm{DP}}=\frac{0.18 \lambda}{\pi} \int_{0}^{\infty} \operatorname{Re}\left[s_{a}{ }^{(0)}-s_{b}{ }^{(0)}\right] A_{7} N(D) d D,
$$

where $Z$ is the reflectivity factor at the horizontal polarization and $K_{\mathrm{DP}}$ is the specific differential phase $\left({ }^{\circ} \mathrm{km}^{-1}\right)$. In (12) and (13), $\lambda$ is the radar wavelength (in $\mathrm{mm}$ ), whereas the coefficients $A_{2}, A_{4}$, and $A_{7}$ are the angular moments of the canting angle distributions of hydrometeors:

$A_{2}=0.25\left(1-r^{2}\right)$,

$A_{4}=\left(0.375-0.5 r+0.125 r^{4}\right)\left(0.375+0.5 r+0.125 r^{4}\right)$,

and

$$
A_{7}=0.5 r(1+r) \text {, }
$$

where $r=\exp \left(-2 \sigma^{2}\right)$ and $\sigma$ is the width of the canting angle distribution (in the expression for $r, \sigma$ is in radians; for convenience, we express $\sigma$ in degrees throughout the text). Scattering amplitudes $s_{a, b}(\mathrm{~mm})$ are determined in the Rayleigh approximation for which the backward and forward scattering amplitudes [denoted with superscripts $(\pi)$ and $(0)$, respectively] are the same [i.e., $\left.s_{a, b}^{(\pi)}=s_{a, b}^{(0)}\right]$ and can be expressed as (van de Hulst 1981)

$$
s_{a, b}^{(\pi)}=s_{a, b}^{(0)}=\frac{\pi^{2} D^{3}}{6 \lambda^{2}} \frac{\varepsilon-1}{L_{a, b}(\varepsilon-1)+1},
$$

with $\varepsilon$ representing the dielectric constant of dry snow (determined from the Maxwell Garnett mixing formula); $L_{a, b}$ are the shape parameters given by

$$
\begin{aligned}
& L_{b}=\frac{1+g^{2}}{g^{2}}\left(1-\frac{\arctan g}{g}\right), \quad g=\sqrt{\frac{a^{2}}{b^{2}}-1,} \text { and } \\
& L_{a}=\frac{1-L_{b}}{2} .
\end{aligned}
$$

Here, $b / a$ is the aspect ratio of an oblate particle; hence, $b<a$.

The specific differential phase $K_{\mathrm{DP}}$ strongly depends on the particle shape and orientation (see the appendix), while $Z$ is not much affected by these factors. Nonetheless, as shown by Hogan et al. (2012), the polarimetric radar variables in aggregated snow consisting of irregular ice particles can be computed with reasonable accuracy by modeling the scatterers as oblate spheroids with a vertical rotation axis (i.e., $\sigma=0^{\circ}$ ) and an aspect ratio of 0.6. Numerous studies of ice with aircraft in situ probes demonstrate that irregular aggregated particles compose the bulk (up to $90 \%$ ) of the snow (Korolev et al. 2000) and, if larger than about $0.07 \mathrm{~mm}$, typically have an axis ratio between 0.5 and 0.7 (Korolev and Isaac 2003). Garrett et al. (2015) found that the median axis ratio of unrimed aggregates is equal to 0.60 versus 0.70 for moderately rimed snowflakes in the observations with the multiple angle snow camera (MASC; particles $>1 \mathrm{~mm}$ were examined). Thus, in our computations of $K_{\mathrm{DP}}$ and $Z$ from the 2DVD measurements, we utilize an axis ratio $b / a=0.65$ and $\sigma=0^{\circ}$.

\section{Parameterization of the $Z-S$ and $Z-I W C$ relations for dry snow}

\section{a. Parameterization of the $Z-S$ and $Z-I W C$ relations}

Following the approach of Rasmussen et al. (2003), theoretical $Z-S$ and $Z$-IWC relations can be derived. As shown in the appendix, these relations are parameterized by the intercept $N_{0 \mathrm{~s}}$ and the degree of riming, $f_{\text {rim }}$ :

$$
S=2.26 \times 10^{-3} a_{u} f_{\text {rim }}^{0.07} N_{0 \mathrm{~s}}^{0.37} Z^{0.63}
$$

and

$$
\mathrm{IWC}=4.95 \times 10^{-4} f_{\text {rim }}^{-0.19} N_{0 \mathrm{~s}}^{0.4} Z^{0.6} .
$$

It follows from (19) and (20) that the multipliers in the power-law $S-Z$ and IWC- $Z$ relations are almost entirely dependent on the intercept $N_{0 \mathrm{~s}}$ of the exponential size distribution and are practically insensitive to the degree of riming $f_{\text {rim. }}$.

We use our disdrometer dataset obtained from 16 snowstorms in Oklahoma to estimate $S$, IWC, $N_{0 \mathrm{~s}}$, and $Z$ and to derive empirical $S\left(N_{0 \mathrm{~s}}, Z\right)$ and $\operatorname{IWC}\left(N_{0 \mathrm{~s}}, Z\right)$ 


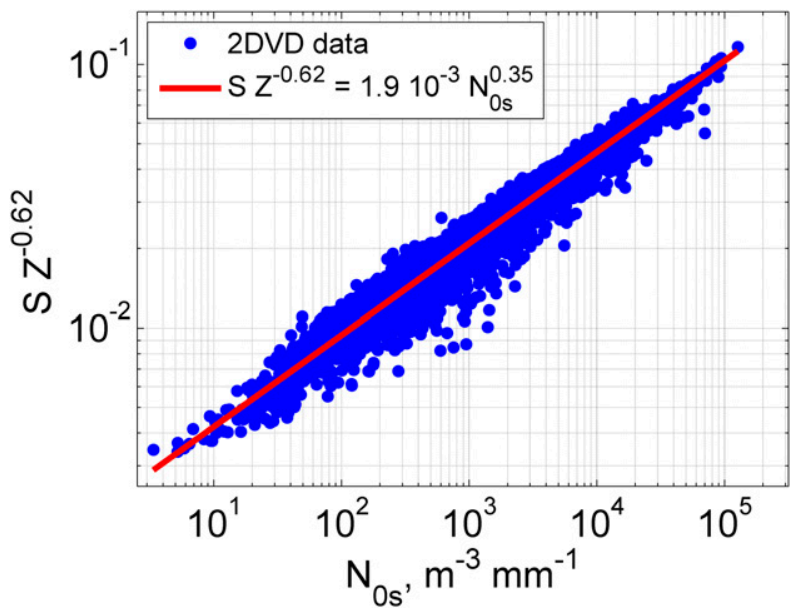

FIG. 2. Scatterplot of $N_{0 \mathrm{~s}}$ vs $S \times Z^{-0.62}\left(\log _{10}\right.$ scale; correlation coefficient $=0.978$ ) from 2DVD estimations and computations (blue dots). The best fit to $2 \mathrm{DVD}$ data, $S \times Z^{-0.62}=1.9 \times 10^{-3} N_{0 \mathrm{~s}}^{0.35}$, is overlaid by the red line.

relations. As a first step, we plot $N_{0 \mathrm{~s}}$ versus the ratio $S / Z^{q}$ with various values of the exponent $q$ to find an optimal value of $q$ that yields the highest correlation coefficient between $N_{0 s}$ and $S / Z^{q}$. As expected, the correlation is indeed very high and the maximal correlation coefficient (0.978) is achieved for $q=0.62$. The corresponding scatterplot of $S / Z^{0.62}$ versus $N_{0 \mathrm{~s}}$ (Fig. 2) clearly demonstrates that the value of $S$ can vary by more than an order of magnitude for a given $Z$ depending on $N_{0 \mathrm{~s}}$, where the later can change four orders of magnitude. The best linear fit to the scatterplot in Fig. 2 is

$$
S=1.9 \times 10^{-3} N_{0 \mathrm{~s}}^{0.35} Z^{0.62},
$$

with the exponents of $N_{0 \mathrm{~s}}$ and $Z$ in excellent agreement with theoretical predictions specified in (19) (0.37 and 0.63 , respectively).

A similar analysis for IWC yields

$$
\mathrm{IWC}=5.26 \times 10^{-4} N_{0 \mathrm{~s}}^{0.38} Z^{0.58},
$$

and the corresponding scatterplot is presented in Fig. 3. Again, the exponents in the empirical best fit are very consistent with those in the theoretical (20) and agree well with the results of in situ measurements with aircraft probes in various types of clouds. The latter are summarized in the studies of Hogan et al. (2012) and Delanoë et al. (2014), where the relations IWC $\sim N_{0 \mathrm{~s}}^{0.4} Z^{0.6}$ and IWC $\sim N_{0 \mathrm{~s}}^{0.42} Z^{0.58}$ were suggested.

The strong dependence of the multipliers in the $S-Z$ and IWC- $Z$ relations on the concentration of snow particles (which can be approximated by the intercept $N_{0 \mathrm{~s}}$ ) precludes their effective use for the quantification of snow. The ubiquitous presence of dual-polarization

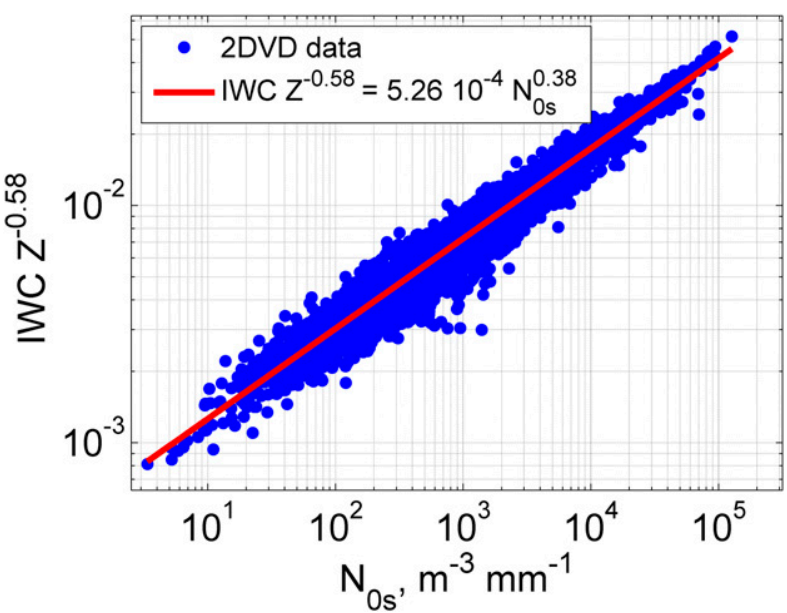

FIG. 3. Scatterplot of $N_{0 \mathrm{~s}}$ vs IWC $\times Z^{-0.58}\left(\log _{10}\right.$ scale; correlation coefficient $=0.977$ ) from 2DVD estimations and computations (blue dots). The best fit to 2DVD data, IWC $\times Z^{-0.58}=$ $5.26 \times 10^{-4} N_{0 \mathrm{~s}}^{0.38}$, is overlaid by the red line.

weather radars motivates the exploration of alternatives. One of these is to classify snow types using polarimetric variables and then apply $S(Z)$ or $\operatorname{IWC}(Z)$ relations corresponding to the particular snow type. Differential reflectivity $Z_{\mathrm{DR}}$ can be a good candidate for snow classification but not for quantification. The quantity $Z_{\mathrm{DR}}$ is insensitive to concentrations of snowflakes, which cause the largest uncertainty in the $S(Z)$ or $\operatorname{IWC}(Z)$ relations, as Figs. 2 and 3 demonstrate.

Another possibility is to use $K_{\mathrm{DP}}$, which is directly proportional to $N_{0 s}$. Vivekanandan et al. (1994) and Ryzhkov et al. (1998) reported promising results in the estimation of IWC from $K_{\mathrm{DP}}$ for pristine or lightly aggregated ice crystals. That approach may not work well for aggregated or irregular snowflakes because $K_{\mathrm{DP}}$ is proportional to the first moment of PSD whereas $S$ and IWC are close to the second moment of PSD for lowdensity snow (see the appendix). Nevertheless, we tried this path and came up with the following $S\left(K_{\mathrm{DP}}\right)$ and IWC $\left(K_{\mathrm{DP}}\right)$ relations at $\mathrm{S}$ band using our disdrometer dataset:

$$
\begin{aligned}
S\left(K_{\mathrm{DP}}\right) & =55.63 K_{\mathrm{DP}}^{1.08} \quad \text { and } \\
\operatorname{IWC}\left(K_{\mathrm{DP}}\right) & =14.44 K_{\mathrm{DP}}^{1.05} .
\end{aligned}
$$

Because exponential size distributions are characterized with two parameters, $N_{0 \mathrm{~s}}$ and $\Lambda_{s}$, it is possible to estimate these from two radar variables. We chose the combination of $Z$ and $K_{\mathrm{DP}}$, and from the same disdrometer dataset, we obtained the following relations:

$$
N_{0 \mathrm{~s}}\left(K_{\mathrm{DP}}, Z\right)=15.3 \times 10^{7} K_{\mathrm{DP}}^{1.72} Z^{-0.79}
$$



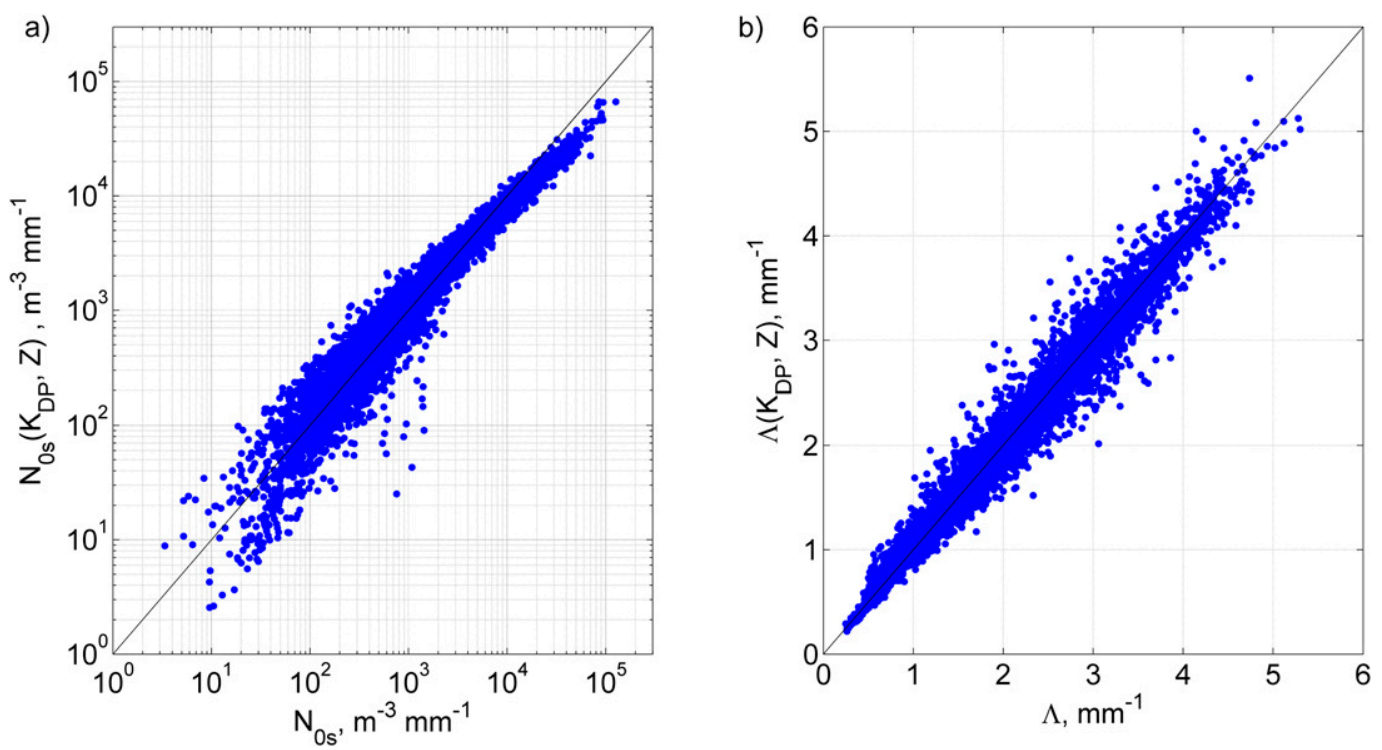

FIG. 4. Scatterplots of (a) $N_{0 \mathrm{~s}}(2 \mathrm{DVD})$ vs $N_{0 \mathrm{~s}}\left(K_{\mathrm{DP}}, Z\right)\left(\log _{10}\right.$ scale; correlation coefficient $\left.=0.971\right)$ and (b) $\Lambda_{s}(2 \mathrm{DVD})$ vs $\Lambda_{s}\left(K_{\mathrm{DP}}, Z\right)$ (correlation coefficient $\left.=0.985\right)$.

$$
\Lambda_{s}\left(K_{\mathrm{DP}}, Z\right)=39 K_{\mathrm{DP}}^{0.36} Z^{-0.35} .
$$

Both parameters exhibit a tight fit (Fig. 4). The high correlation with their 2DVD estimates from the method of moments $\left(0.971\right.$ for $N_{0 \mathrm{~s}}$ and 0.985 for $\Lambda_{s}$ ) suggests that (25) and (26) may enable the polarimetric radar retrieval of snow microphysical parameters.

From (25) and (26) it is easy to compute the exponential snow PSD, from which in turn the values of $S$ and IWC can be computed. The disadvantage of this type of approach is that the PSD is assumed to be exponential and thus is not directly measured. Another possibility is to use direct combination of $Z$ and $K_{\text {DP }}$ to express $S$ and IWC. The reasoning is that $Z$ is close to the fourth moment while $K_{\mathrm{DP}}$ is proportional to the first moment of PSD for a low-density (aggregated) snow. Therefore, the product of $K_{\mathrm{DP}}$ and $Z$ with certain exponents might be more directly related to the second moment of PSD, and thus we search for solutions of the form $S \sim K_{\mathrm{DP}}^{\alpha_{1}} Z^{\beta_{1}}$ and $\mathrm{IWC} \sim K_{\mathrm{DP}}^{\alpha_{2}} Z^{\beta_{2}}$.

A direct approach independent of the two parameters of PSD yields the $S$ and IWC via multivariate linear fitting or the logarithms of $S$, IWC, $Z$, and $K_{\mathrm{DP}}$. This way, the following $S\left(K_{\mathrm{DP}}, Z\right)$ and $\operatorname{IWC}\left(K_{\mathrm{DP}}, Z\right)$ are obtained from our disdrometer dataset:

$$
\begin{aligned}
& S\left(K_{\mathrm{DP}}, Z\right)=1.48 K_{\mathrm{DP}}^{0.61} Z^{0.33} \text { and } \\
& \operatorname{IWC}\left(K_{\mathrm{DP}}, Z\right)=0.71 K_{\mathrm{DP}}^{0.65} Z^{0.28} .
\end{aligned}
$$

\section{b. Relation between IWC and $S$}

Heymsfield et al. (2016) showed that the logarithms of IWC and $S$ are linearly related, implying that the relation on a linear scale follows a power law. Indeed, estimated values from disdrometer data (Fig. 5) indicate a slightly quadratic fit of the form $S=$ 0.406 IWC $^{2}+3.34$ IWC -0.001 (black line in Fig. 5; this relation is valid for IWC $\left.>0.00042 \mathrm{~g} \mathrm{~m}^{-3}\right)$. But, the linear expression $S=3.66 \times$ IWC (magenta line) fits the data fairly well. The correlation coefficient between IWC and $S$ is 0.991 . The results from Heymsfield et al. (2016), depicted by red and green lines, are in good agreement with our fits at IWC less than about $0.6 \mathrm{~g} \mathrm{~m}^{-3}$ and slightly overestimate $S$ at higher IWCs.

\section{Disdrometer measurements/estimations and expected values of $S$ and IWC}

\section{a. Oklahoma 2DVD measurements}

The Oklahoma disdrometer dataset was used to compare the performances of the three types of algorithms: based on the combination of $Z$ and $K_{\mathrm{DP}}$ [see (27) and (28)], using a sole $K_{\mathrm{DP}}$ [see (23) and (24)], and traditional $Z$-based relations. The latter relations are also derived from our Oklahoma dataset to make fair and meaningful comparisons:

$$
\begin{aligned}
S(Z) & =0.019 Z^{0.64} \text { and } \\
\operatorname{IWC}(Z) & =0.0067 Z^{0.61} .
\end{aligned}
$$




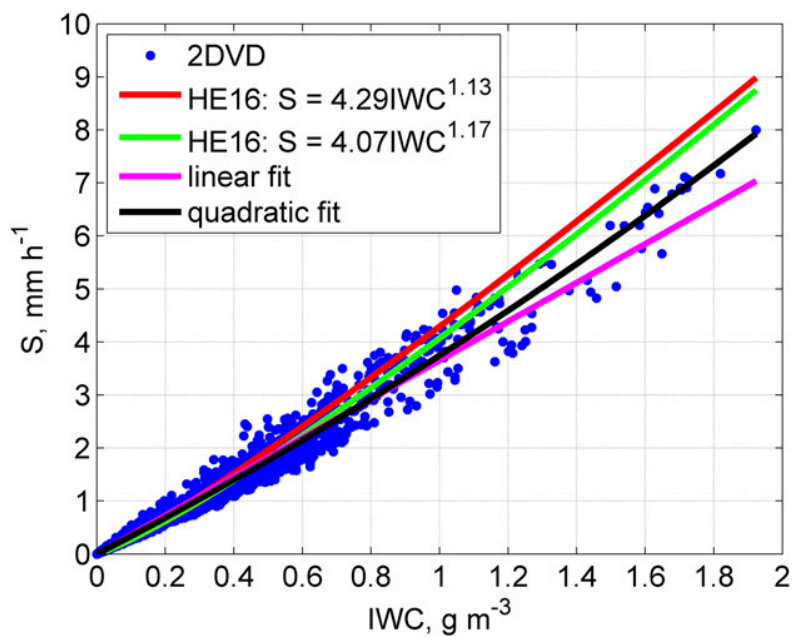

FIG. 5. Scatterplot of IWC vs $S$ : blue dots represent 2DVD measurements, red and green lines show the Heymsfield et al. (2016) relations (herein HE16), and magenta and black lines represent the linear and quadratic least squares fits to the 2DVD data, respectively. The correlation coefficient between the 2DVD-measured IWC and $S$ is 0.991 .

For further validation and verification, we used the data from the same 2DVD instrument located in Colorado ( $20 \mathrm{~km}$ east of Grand Junction, $\sim 3000 \mathrm{~m}$ MSL) during the 2013 winter. We developed the $S$ and IWC relations for Colorado, $S_{\mathrm{CO}}\left(K_{\mathrm{DP}}, Z\right)$ and $\mathrm{IWC}_{\mathrm{CO}}\left(K_{\mathrm{DP}}, Z\right)$, and found that these slightly differ from the Oklahoma relations. The data are derived from a sample of six storms (aggregated snow) that had reliable heated rain gauge measurements (SWE $>1 \mathrm{~mm}$ ). These results are also applied to the Oklahoma dataset along with three previously described methods. Although we had the data from the same type of instrument (possibly a later model) located in Canada, we did not use it for cross verification of the Oklahoma dataset because of the small data sample (consisting of only a few storms). Instead, we used the Oklahoma relations on the Canadian dataset for further verification.

The scatterplots of snow rates directly estimated by the disdrometer versus expected values from the three methods computed using disdrometer data are displayed in Fig. 6 for the Oklahoma dataset. The width of the $S(Z)$ versus $S(2 \mathrm{DVD}$ ) scatterplot (green dots in Fig. 6) is prohibitively large because $Z$ is the fourth moment of the particle size distribution for aggregated snow. Moreover, the $S(Z)$ tends to overestimate light and moderate snowfall whereas it underestimates high snow rates $\left(S>5 \mathrm{~mm} \mathrm{~h}^{-1}\right)$. This is caused by the dependence of the multiplier in the $S(Z)$ relation on the parameters of the PSD. The $S\left(K_{\mathrm{DP}}\right)$ estimate (blue dots in Fig. 6) shows smaller, but still significant, scatter around the one-to-one line relative to that from the $S(Z)$. On the other hand, the scatterplot of the

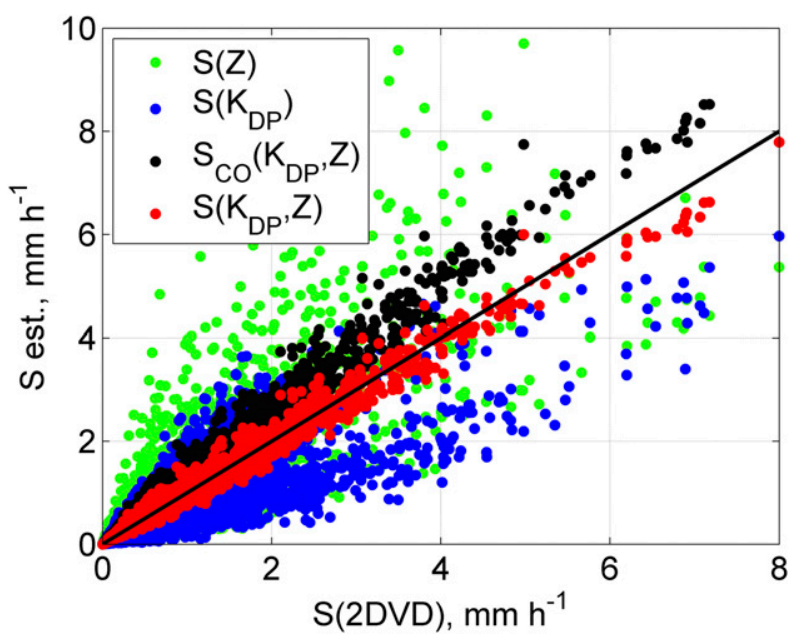

FIG. 6. Scatterplots of $S(2 \mathrm{DVD})$ vs $S(Z)$ (green dots), $S(2 \mathrm{DVD})$ vs $S\left(K_{\mathrm{DP}}\right)$ (blue dots), $S(2 \mathrm{DVD})$ vs $S_{\mathrm{CO}}\left(K_{\mathrm{DP}}, Z\right)$ (black dots, where subscript $\mathrm{CO}$ denotes the $\mathrm{CO}$ dataset derived from six storms), and $S(2 \mathrm{DVD})$ vs $S\left(K_{\mathrm{DP}}, Z\right)$ (red dots). The correlation coefficients between $S(2 \mathrm{DVD})$ and $S(Z), S\left(K_{\mathrm{DP}}\right), S_{\mathrm{CO}}\left(K_{\mathrm{DP}}, Z\right)$, and $S\left(K_{\mathrm{DP}}, Z\right)$ are $0.862,0.891,0.995$, and 0.995 , respectively.

$S\left(K_{\mathrm{DP}}, Z\right)$ versus $S(2 \mathrm{DVD})$ is very tight, concentrated along the one-to-one line, and is not biased.

For comparison and validation of our results, we derived (the same procedure as for the Oklahoma data) an $S_{\mathrm{CO}}\left(K_{\mathrm{DP}}, Z\right)=1.88 K_{\mathrm{DP}}^{0.61} Z^{0.34}$ relation from the Colorado data and applied it to the Oklahoma dataset. The scatter between the points (black dots) is comparable to the Oklahoma $S\left(K_{\mathrm{DP}}, Z\right)$ scatter and has a very tight fit; the Colorado relation is positively biased, with overestimation of $S$ by about $27 \%$ (in agreement with the ratio of the relations' multipliers). The exponents of both relations are practically the same, whereas the relations' multipliers differ. This implies that multipliers of these relations may need to be adjusted according to the geographical location or perhaps altitude (environmental conditions such as, e.g., temperature).

Similar scatterplots for ice water content are displayed in Fig. 7. The IWC $(Z)$ (green dots) versus IWC(2DVD) displays relatively large scatter and underestimates IWC for larger ice water contents (IWC $>1.3 \mathrm{~g} \mathrm{~m}^{-3}$ ), while the $\operatorname{IWC}\left(K_{\mathrm{DP}}, Z\right)$ (red dots) is similar to $\operatorname{IWC}\left(K_{\mathrm{DP}}\right)$ (blue dots); the former shows very small scatter about the one-to-one line. The $\operatorname{IWC}\left(K_{\mathrm{DP}}, Z\right)$ agrees much better with the direct 2DVD estimates than the $\operatorname{IWC}(Z)$ and has a tighter fit than the $\operatorname{IWC}\left(K_{\mathrm{DP}}\right)$. In the same manner, as for $S$, we have derived the relation for $\operatorname{IWC}_{\mathrm{CO}}\left(K_{\mathrm{DP}}, Z\right)=0.73 K_{\mathrm{DP}}^{0.64} Z^{0.29}$ from the six Colorado storms. The Colorado IWC relation, similarly to the Oklahoma relation, exhibits the tight fit when applied to the Oklahoma dataset (black dots). The exponents in both the Oklahoma and Colorado relations are 


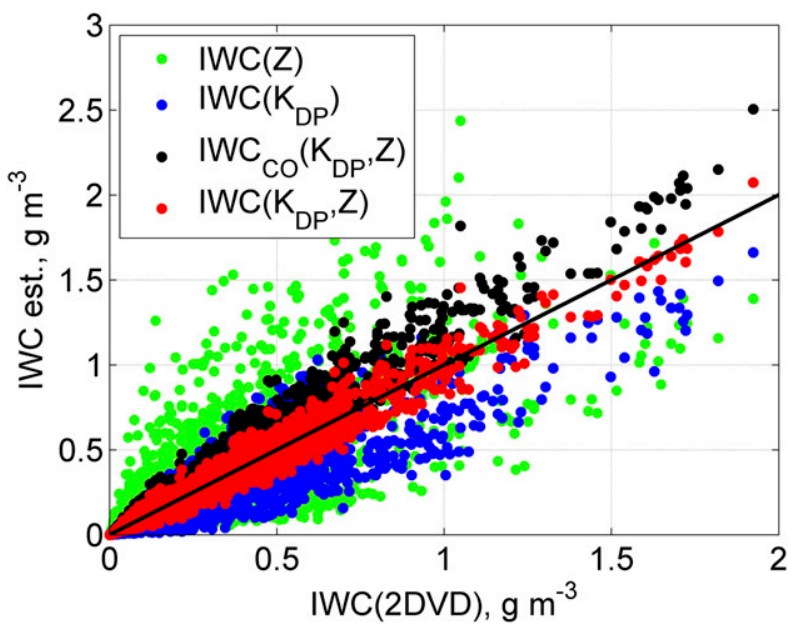

FIG. 7. Scatterplots of $\operatorname{IWC}(2 \mathrm{DVD})$ vs $\operatorname{IWC}(Z)$ (green dots), IWC(2DVD) vs $\operatorname{IWC}\left(K_{\mathrm{DP}}\right)$ (blue dots), IWC(2DVD) vs $\mathrm{IWC}_{\mathrm{CO}}\left(K_{\mathrm{DP}}, Z\right)$ (black dots, where subscript $\mathrm{CO}$ denotes the $\mathrm{CO}$ dataset derived from six storms), and IWC(2DVD) vs IWC( $K_{\mathrm{DP}}$ $Z$ ) (red dots). The correlation coefficients between IWC(2DVD) and $\operatorname{IWC}(Z), \operatorname{IWC}\left(K_{\mathrm{DP}}\right), \operatorname{IWC}_{\mathrm{CO}}\left(K_{\mathrm{DP}}, Z\right)$, and $\operatorname{IWC}\left(K_{\mathrm{DP}}, Z\right)$ are $0.826,0.932,0.988$, and 0.990 , respectively.

practically the same, while the multiplier in the Colorado relation is $\sim 4 \%$ higher. This result is encouraging because the relation derived from the data from one region seems to be applicable to data from a different region.

\section{b. Colorado 2DVD measurements}

To further validate the polarimetric snow estimation relations, measurements obtained in Colorado during the winter of 2012/13 are presented. For brevity, only two cases are evaluated: one with light-to-moderate snow accumulations and the other with high accumulations. Nonetheless, the principal findings are representative of the whole set of 30 events. The Colorado relations (listed in the previous section) are used for verification and comparisons with the "general" $S\left(K_{\mathrm{DP}}, Z\right)$ relation derived from the Oklahoma data [see (27)]. There are several radar $S(Z)$ relations available for this area (such as Vasiloff 1997; Wolfe and Snider 2012, 2013; among others), but we have used 2DVD-derived $S_{\mathrm{CO}}(Z)=0.024 Z^{0.78}$ for consistency and fair comparison. For reference, we have tested the relation of Wolfe and Snider (2012). Their relation gave results that are comparable to those of 2DVD-derived $S_{\mathrm{CO}}(Z)$, and was within $\pm 10 \%-15 \%$ of the total accumulation measured by the heated rain gauge for two chosen Colorado cases. For brevity, the analysis of the $S\left(K_{\mathrm{DP}}\right)$ is omitted.

\section{1) 11 JANUARY 2013 CASE}

Two major episodes of snow with different PSD types occurred during the event (Fig. 8). During the period from 0400 to 1200 UTC, relatively large particle sizes $(D<8 \mathrm{~mm})$ and smaller concentrations are detected (Fig. 8a; concentrations can be estimated from the color scale, where warmer colors indicate higher concentrations). Later, from 1800 to 2200 UTC the particles are smaller $(D<4 \mathrm{~mm})$ but have higher maximal concentrations. The reflectivity factor $Z$ computed from $2 D V D$ measurements is higher during the first period with the maximum $\sim 34 \mathrm{dBZ}$ as compared with the maximum $\sim 29 \mathrm{~dB} Z$ during the second (Fig. 8b). Large particles in conjunction with relatively lower concentrations produce higher reflectivities during the first episode. In the later period with smaller particles, $Z$ is lower even though at times the concentrations are an order of magnitude higher than during the previous period. This has a large impact on the $S_{\mathrm{CO}}(Z)$ and $S\left(K_{\mathrm{DP}}, Z\right)$ estimates, as seen in Fig. 8c, where $S$ directly estimated by the disdrometer is also depicted.

Because $Z$ is proportional to the fourth PSD moment in aggregated snow, the $S_{\mathrm{CO}}(Z)$ estimate does not capture adequately the variability of the PSD. This is why $S_{\mathrm{CO}}(Z)$ is significantly larger than $S(2 \mathrm{DVD})$ or $S\left(K_{\mathrm{DP}}, Z\right)$ during the period of larger snowflakes (0900-0930 UTC) (Fig. 8c). The opposite happens during the period from 1800 to 1900 UTC when smaller particles and higher concentrations are observed and $S(Z)$ has a negative bias. Also note the discrepancy between the $S\left(K_{\mathrm{DP}}, Z\right)$ and the $S$ (2DVD) during the same period. This is caused by the nonaggregate nature of the precipitation, as indicated by the larger values of $Z_{\mathrm{DR}}$ (not shown), for which the polarimetric relations are not tuned. Overall, the $S\left(K_{\mathrm{DP}}, Z\right)$ estimate accounts better for the variations in the PSDs and microphysics; hence, it is closer to the disdrometerestimated $S$ (except for the nonaggregate precipitation period). A heated rain gauge collocated with the disdrometer registered a total snow water equivalent of $6.6 \mathrm{~mm}$; the 2DVD particle filtering threshold was chosen such that the 2DVD accumulation matched this value. The snow accumulation from $S\left(K_{\mathrm{DP}}, Z\right)$ is about $\sim 23 \%$ lower than the "true" accumulation estimated by the disdrometer, whereas the $S_{\mathrm{CO}}(Z)$ accumulation is $\sim 15 \%$ higher (Fig. 8d). This result is mostly caused by the precipitation during the period from 1800 to 1900 UTC, where both $S_{\mathrm{CO}}(Z)$ and $S\left(K_{\mathrm{DP}}, Z\right)$ underestimate the snow amounts, which falsely improves the $S_{\mathrm{CO}}(Z)$ performance. Before this period of non-aggregates, $S\left(K_{\mathrm{DP}}, Z\right)$ was much closer to the 2DVD estimate than $S_{\mathrm{CO}}(Z)$.

The scatterplots of $S_{\mathrm{CO}}(Z)$ versus $S(2 \mathrm{DVD})$ (green dots), $S\left(K_{\mathrm{DP}}, Z\right)$ versus $S(2 \mathrm{DVD})$ (red dots), and $S_{\mathrm{CO}}\left(K_{\mathrm{DP}}, Z\right)$ versus $S(2 \mathrm{DVD})$ (blue dots) are shown in Fig. 9. The $S_{\mathrm{CO}}(Z)$ exhibits large spread, mainly because $Z$ is proportional to the fourth moment of the PSD in aggregated snow. In contrast, the $S\left(K_{\mathrm{DP}}, Z\right)$ produces 

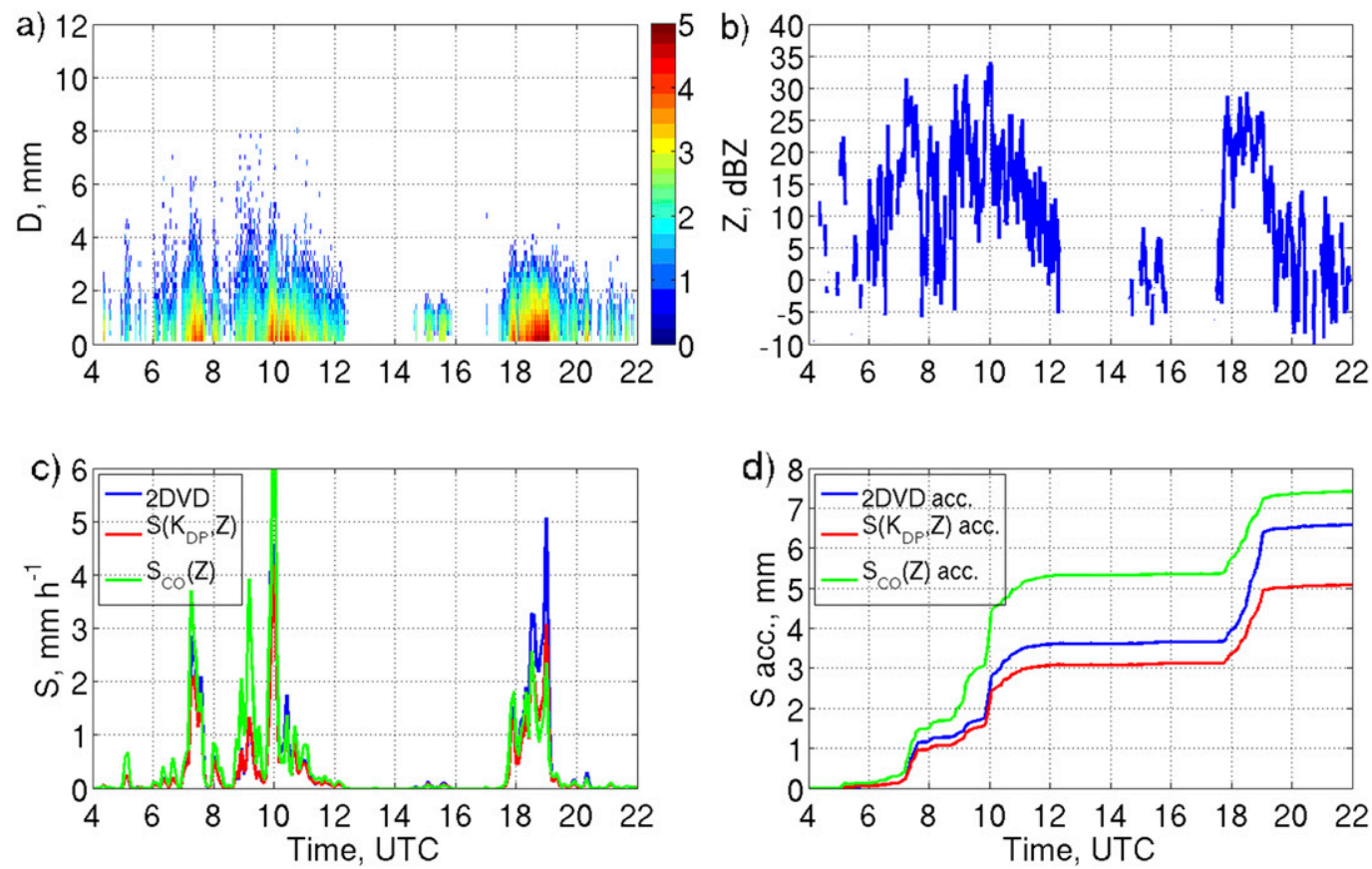

FIG. 8. Evolution of (a) PSD in $\log _{10}$ scale indicated by the color bar $\left[\log _{10}\left(\mathrm{~m}^{-3} \mathrm{~mm}^{-1}\right)\right]$, where the dark-blue to dark-red color scale represents low to high particle concentrations; (b) $Z$; (c) $S(2 \mathrm{DVD}), S\left(K_{\mathrm{DP}}, Z\right)$, and $S_{\mathrm{CO}}(Z)$ (blue, red, and green lines, respectively); and (d) snow accumulations measured by 2DVD and estimated via $S\left(K_{\mathrm{DP}}, Z\right)$ and $S_{\mathrm{CO}}(Z)$ (blue, red, and green curves, respectively), for 11 Jan 2013.

relatively small scatter that is closer to the one-to-one line and the $S_{\mathrm{CO}}\left(K_{\mathrm{DP}}, Z\right)$ expected value obtained from six Colorado storms. The correlation coefficient between the 2DVD-estimated $S$ and the $S_{\mathrm{CO}}(Z)$ expected value is 0.833 , whereas the corresponding correlation coefficients for the $S\left(K_{\mathrm{DP}}, Z\right)$ and $S_{\mathrm{CO}}\left(K_{\mathrm{DP}}, Z\right)$ expected values are both 0.983 .

\section{2) 28 JANUARY 2013 CASE}

During this event, the snowfall accumulation measured with the collocated heated rain gauge was $22.9 \mathrm{~mm}$. The PSDs had highly variable sizes (maximal diameters $\sim 12 \mathrm{~mm}$ ) and concentrations (Fig. 10a). The highest reflectivity factor of $\sim 36 \mathrm{dBZ}$ was measured at $\sim 1445$ UTC (Fig. 10b) and was attributed to a relatively high number of large particles in comparison with the number of small particles.

Snowfall rates $S\left(K_{\mathrm{DP}}, Z\right)$ (Fig. $10 \mathrm{c}$, red line) are slightly underestimated but remain closer to the 2DVD estimations (Fig. 10c, blue line) than do the $S_{\mathrm{CO}}(Z)$ rates (Fig. 10c, green line). As in the previous case, $S_{\mathrm{CO}}(Z)$ is heavily weighted by the particle sizes, producing higher values than $S(2 \mathrm{DVD})$ and $S\left(K_{\mathrm{DP}}, Z\right)$ at $0600 \mathrm{UTC}$ and from 1300 until 1900 UTC.

Whenever the concentrations are high $(\sim 0700$ and 0900 UTC), even with moderate $Z, S_{\mathrm{CO}}(Z)$ significantly underestimates the snow rate, as in the previous examples. The difference between the accumulations from $S\left(K_{\mathrm{DP}}, Z\right)$ and $S(2 \mathrm{DVD})$ is $\sim 25 \%$, but the shapes of the curves are very similar (Fig. 10d, red and blue lines), whereas the estimate from $S_{\mathrm{CO}}(Z)$ (Fig. 10d, green line) is not as consistent with the measurements although it underestimates the total amount by only $\sim 7 \%$. Despite such a small difference in a snow totals, the instantaneous LWE from disdrometer measurements and $S_{\mathrm{CO}}(Z)$ show large discrepancies. Thus, in this case, the good agreement in the accumulations is fortuitous.

The scatterplots of $S(2 \mathrm{DVD})$ versus $S_{\mathrm{CO}}(Z), S(2 \mathrm{DVD})$ versus $S\left(K_{\mathrm{DP}}, Z\right)$, and $S(2 \mathrm{DVD})$ versus $S_{\mathrm{CO}}\left(K_{\mathrm{DP}}, Z\right)$ are shown in Fig. 11. Again, $S_{\mathrm{CO}}(Z)$ exhibits a very large dispersion around the one-to-one line (green dots), which is in accord with the previous event analysis. The $S\left(K_{\mathrm{DP}}, Z\right)$ value is biased slightly to moderately and displays small dispersion (red dots). The scatterplot is relatively close to the $45^{\circ}$ line and the $S_{\mathrm{CO}}\left(K_{\mathrm{DP}}, Z\right)$ results derived from the Colorado dataset (blue dots). Although the $S\left(K_{\mathrm{DP}}, Z\right)$ underestimates the total SWE amount, the correlation with $S(2 \mathrm{DVD})$ is high (0.987) relative to that for $S_{\mathrm{CO}}(Z)$, which is significantly lower (0.796). This means that the bias in the $S\left(K_{\mathrm{DP}}, Z\right)$ estimate could be removed by simply adjusting the multiplier of the relation according to the regional climatology (or altitude). This is consistent with the 


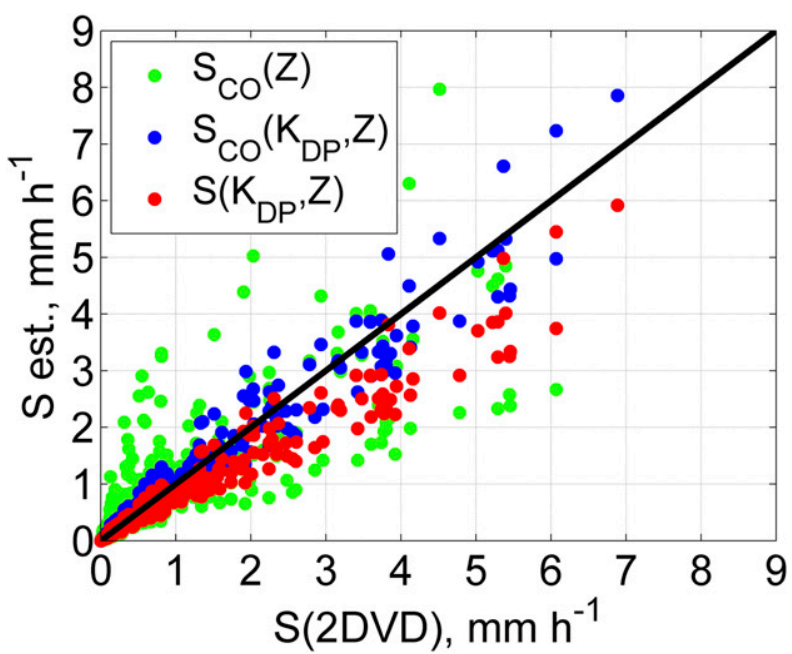

FIG. 9. Scatterplots of $S(2 \mathrm{DVD})$ vs $S_{\mathrm{CO}}(Z)$ (green dots), $S(2 \mathrm{DVD})$ vs $S_{\mathrm{CO}}\left(K_{\mathrm{DP}}, Z\right)$ (blue dots), and $S(2 \mathrm{DVD})$ vs $S\left(K_{\mathrm{DP}}, Z\right)$ (red dots), for 11 Jan 2013. Correlation coefficients between $S(2 \mathrm{DVD})$ and $S_{\mathrm{CO}}(Z), S_{\mathrm{CO}}\left(K_{\mathrm{DPet}}, Z_{\mathrm{et}}\right)$, and $S\left(K_{\mathrm{DP}}, Z\right)$ are $0.833,0.983$, and 0.983 , respectively.

previous case analysis; thus, $S\left(K_{\mathrm{DP}}, Z\right)$ could potentially produce more realistic results than the $S_{\mathrm{CO}}(Z)$ relation that was specially derived for this region.

\section{c. Canada 2DVD measurements}

The data presented in this section were obtained during the Global Precipitation Measurement Cold Season Precipitation Experiment (GCPEX; SkofronickJackson et al. 2015) in Ontario, Canada, and thus enable verification of the polarimetric relation in a different climate region. In particular, the 25 February 2012 case is classified as a lake-effect snow event. The total SWE amount (measured by an OTT pluvio-weighing precipitation gauge; description available at http://www. ott.com/en-us/products/meteorological-sensors-26/ ott-pluvio2-weighing-rain-gauge-963/) was $\sim 7.6 \mathrm{~mm}$. Here, the "event specific" polarimetric relation [denoted as $S_{\mathrm{et}}\left(K_{\mathrm{DP}}, Z\right)$, thus subscript et] is derived for this particular event and used for comparison. Hence, "general" $S\left(K_{\mathrm{DP}}, Z\right)$ and $S_{\mathrm{et}}\left(K_{\mathrm{DP}}, Z\right)$ have different multipliers in their bivariate power-law relations because $S\left(K_{\mathrm{DP}}, Z\right)$ is derived from the Oklahoma dataset (16 storms), whereas $S_{\mathrm{et}}\left(K_{\mathrm{DP}}, Z\right)$ is obtained from this Canada (Ontario) storm. Also $S_{\text {et }}(Z)$ is derived, which along with $S_{\mathrm{et}}\left(K_{\mathrm{DP}}, Z\right)$ provides independent comparison/verification.

The PSDs' evolution indicates that the maximum sizes of snowflakes are about $10 \mathrm{~mm}$ and the highest concentrations (as indicated by the color bar) are recorded between 0900 and 1200 UTC (Fig. 12a). This event contained multiple snow cells and displayed large variability in the PSDs. The highest reflectivities $[\sim(30-32)$ $\mathrm{dBZ}$; Fig. 12b] occurred during periods when the largest particles were present. It is evident (Fig. 12c) that the $S_{\text {et }}(Z)$ overestimates $S$ when larger particles with lower concentrations are present (from 0300 to 0400 and from 1400 to 1800 UTC) and underestimates snow rate in the opposite situation (green line), whereas $S\left(K_{\mathrm{DP}}, Z\right)$ matches almost perfectly the 2DVD measurements. Even though the largest particle sizes are moderate during the periods of high concentrations, $S_{\text {et }}(Z)$ underestimates $S$ at these times (from 1010 to $1400 \mathrm{UTC})$. The $S\left(K_{\mathrm{DP}}, Z\right)$ closely follows the 2DVD measurements. Accumulations from $S_{\mathrm{et}}(Z)$ are underestimated by $\sim 11 \%$ (Fig. 12d, green line), whereas those from $S\left(K_{\mathrm{DP}}, Z\right)$ are just $\sim 3 \%$ higher (red line) than the reference measurement (blue line).

The scatterplots of $S(2 \mathrm{DVD})$ versus $S_{\mathrm{et}}(Z), S\left(K_{\mathrm{DP}}, Z\right)$, and $S_{\mathrm{et}}\left(K_{\mathrm{DP}}, Z\right)$ are presented in Fig. 13. The $S_{\mathrm{et}}(Z)$ 's (green dots) large dispersion is evident in the scatterplot (correlation coefficient $=0.825$ ). This is in contrast to the $S\left(K_{\mathrm{DP}}, Z\right)$ versus $S(2 \mathrm{DVD})$ scatter diagram (correlation coefficient $=0.988$ ), which has a very small dispersion about the $45^{\circ}$ line. Furthermore, it is very close to the event-specific $S_{\mathrm{et}}\left(K_{\mathrm{DP}}, Z\right)$.

\section{Discussion}

The results of our study demonstrate that the $S\left(K_{\mathrm{DP}}, Z\right)$ and $\operatorname{IWC}\left(K_{\mathrm{DP}}, Z\right)$ relations for snow measurements dramatically reduce the adverse impact of the snow particle size distribution variability on the snow liquid water equivalent and ice water content estimates when compared with traditional $Z$-based relations. The fact that the polarimetric relations derived from the Oklahoma disdrometer dataset perform quite well (with little or no tuning) in different climate regions (Colorado and Ontario) also points to their universal nature. However, these relations have been derived with certain assumptions about snowflake shapes and orientations, which may strongly affect the value of specific differential phase $K_{\mathrm{DP}}$. In other words, the multipliers $\gamma_{1}$ and $\gamma_{2}$ in the $S\left(K_{\mathrm{DP}}, Z\right)$ and $\operatorname{IWC}\left(K_{\mathrm{DP}}, Z\right)$ relations can be quite different for different assumptions about shapes and orientations.

Equation (A26) for $K_{\mathrm{DP}}$ in the appendix shows that $K_{\mathrm{DP}}$ is directly proportional to the difference between shape factors $L_{b}-L_{a}$, which depends on the aspect ratio of snowflakes (Fig. 14). The computations of $K_{\mathrm{DP}}$ in this study were performed for an aspect ratio equal to 0.65 . Korolev and Isaac (2003) found that the aspect ratio of irregular or aggregated ice particles varies between 0.5 and 0.7 and does not depend on the particle size within the range between 100 and $1000 \mu \mathrm{m}$. Figure 14 shows that if the aspect ratio changes within the interval \pm 0.1 about its mean, then the change in $L_{b}-L_{a}$ is about $30 \%$. 

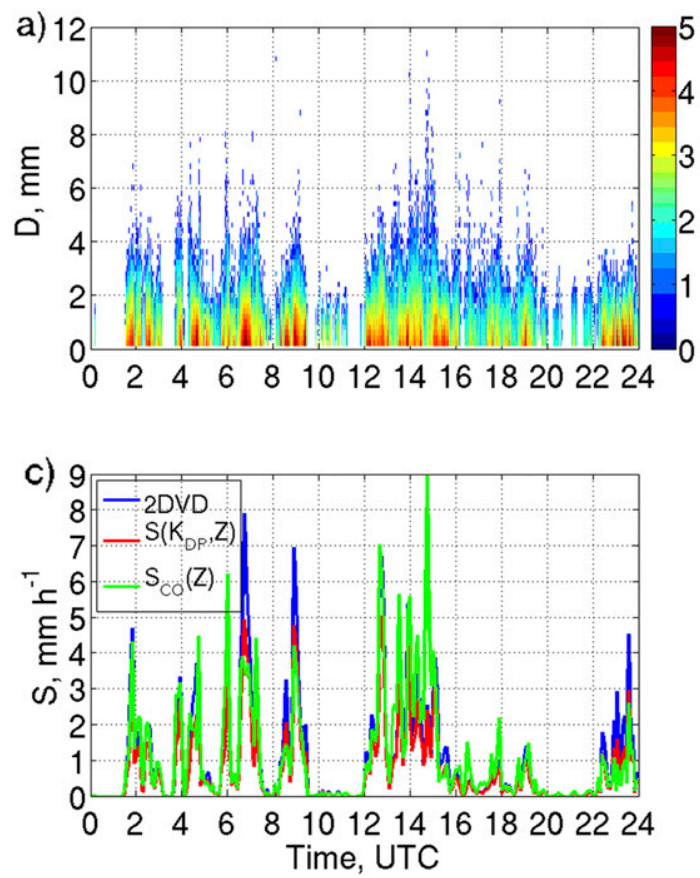
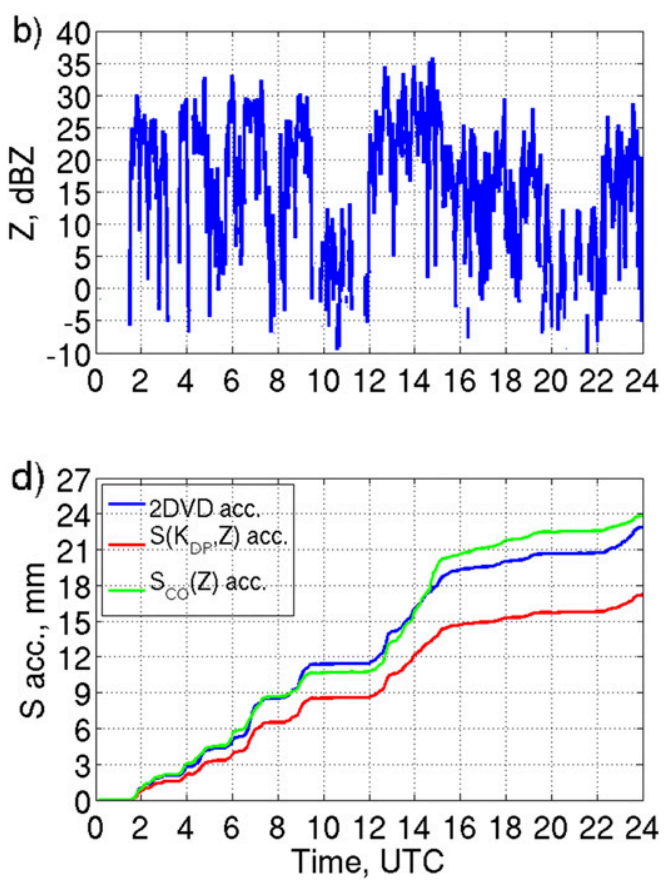

FIG. 10. As in Fig. 8, but for 28 Jan 2013.

This causes errors of about $18 \%-19 \%$ in the estimates of $S$ and IWC because $K_{\mathrm{DP}}$ enters into the relations for $S$ and IWC with exponents close to 0.6 .

Our computations assume that the snowflakes are equioriented [as justified in Hogan et al. (2012)]; that is, the width $\sigma$ of the canting angle distribution is equal to zero. In fact, $K_{\mathrm{DP}}$ is quite sensitive to $\sigma$ and the dependence of $K_{\mathrm{DP}}$ on $\sigma$ is quantified by the factor $r=\exp \left(-2 \sigma^{2}\right)$ in (A26). This means that the coefficients $\gamma_{1}$ and $\gamma_{2}$ are approximately proportional to the factor $\exp \left(-1.2 \sigma^{2}\right)$. The width of the distribution of snowflake orientations is determined by size (or Reynolds number) and atmospheric turbulence. Matrosov et al. (2005) and Melnikov and Straka (2013) found that the parameter $\sigma$ is close to $10^{\circ}$ within a dendritic growth layer (DGL) between air temperatures of $-20^{\circ}$ and $-10^{\circ} \mathrm{C}$. At higher temperatures below DGL, where intense aggregation usually starts, $\sigma$ increases and may reach values of $40^{\circ}$ (Hendry et al. 1987). The corresponding values of $\exp \left(-1.2 \sigma^{2}\right)$ are equal to 0.96 and 0.56 for $\sigma=10^{\circ}$ and $40^{\circ}$. This means that $\gamma_{1}$ and $\gamma_{2}$ should be increased 1.8 times to account for the more random orientations of snowflakes at $\sigma=40^{\circ}$.

Although the degree of snow riming was accounted for in our computations via (7), the Oklahoma dataset includes snow events with relatively light riming. The $\gamma_{1}$ and $\gamma_{2}$ results are also sensitive to the degree of riming $f_{\text {rim. }}$. It follows from (A10), (A11), (A16), and (A26) that $S \sim f_{\text {rim }}^{4 / 3}$, IWC $\sim f_{\text {rim }}$, and $Z, K_{\text {DP }} \sim f_{\text {rim }}^{2}$ for low-density snow. Therefore, the coefficient $\gamma_{1}$ in the
$S\left(K_{\mathrm{DP}}, Z\right)$ relation is proportional to $f_{\text {rim }}^{-0.57}$ and $\gamma_{2}$ in the $\operatorname{IWC}\left(K_{\mathrm{DP}}, Z\right)$ relation is proportional to $f_{\mathrm{rim}}^{-0.86}$. Hence, both coefficients are lower for rimed snow. At the moment, we do not know of a typical variability range of the parameter $f_{\text {rim }}$ in snow. In a similar manner, the decrease in the particles' density by $20 \%$ causes an increase of $\sim 16 \%$ in the polarimetric relation multipliers for $S$ and

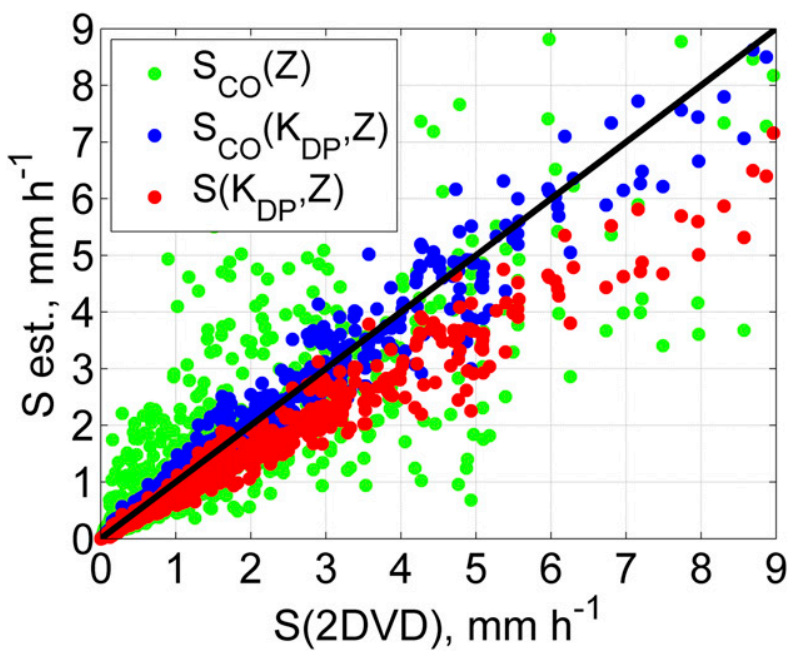

FIG. 11. Scatterplots of $S$ (2DVD) vs $S_{\mathrm{CO}}(Z)$ (green dots), $S(2 \mathrm{DVD})$ vs $S_{\mathrm{CO}}\left(K_{\mathrm{DP}}, Z\right)$ (blue dots), and $S(2 \mathrm{DVD})$ vs $S\left(K_{\mathrm{DP}}, Z\right)$ (red dots), for 28 Jan 2013. Correlation coefficients between $S(2 \mathrm{DVD})$ and $S_{\mathrm{CO}}(Z)$, $S_{\mathrm{CO}}\left(K_{\mathrm{DP}}, Z\right)$, and $S\left(K_{\mathrm{DP}}, Z\right)$ are $0.796,0.987$, and 0.987 , respectively. 

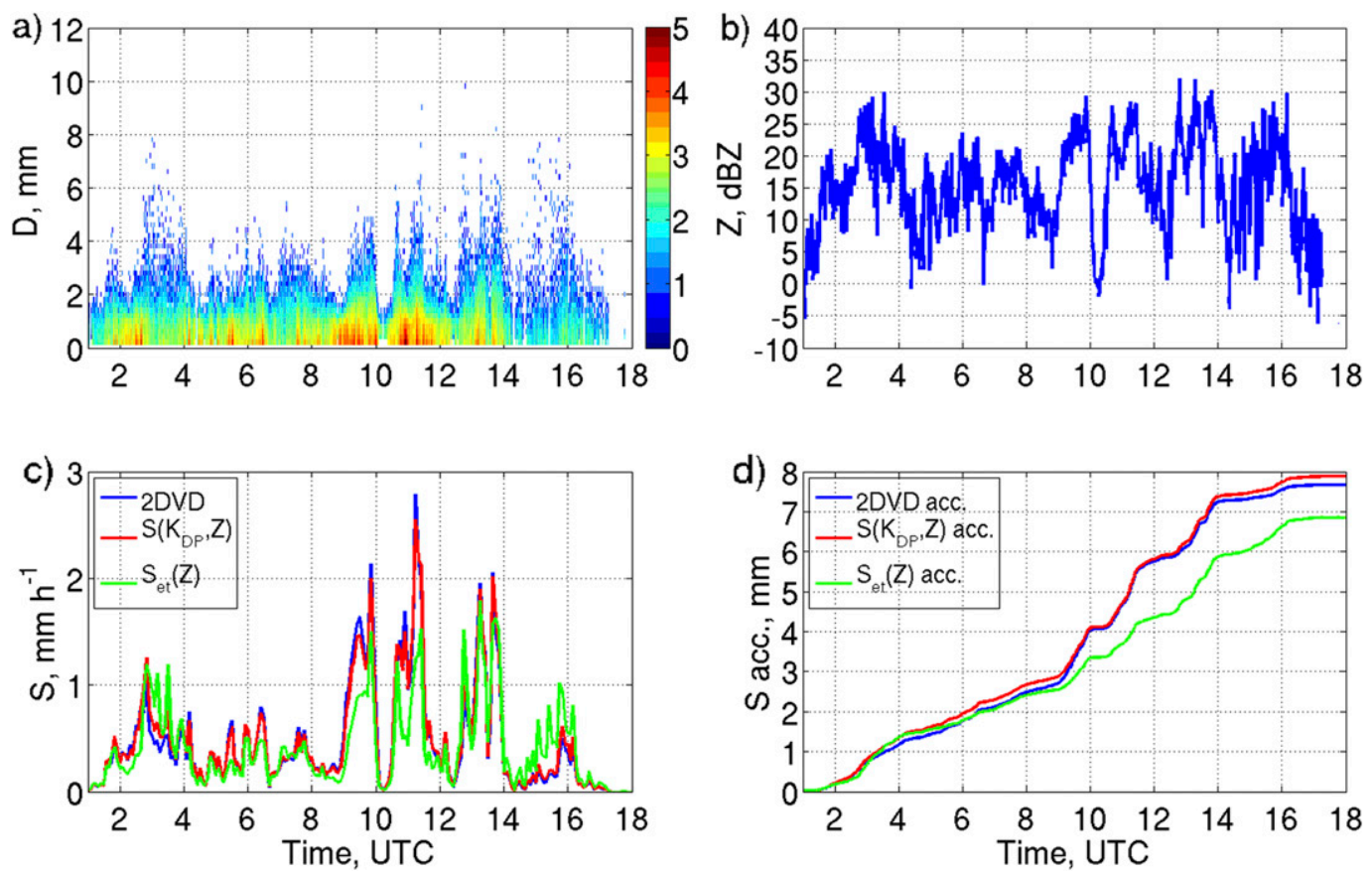

FIG. 12. Evolution of (a) PSD in a $\log _{10}$ scale indicated by the color bar $\left[\log _{10}\left(\mathrm{~m}^{-3} \mathrm{~mm}^{-1}\right)\right]$, where the darkblue to dark-red color scale represents low to high particle concentrations; (b) $Z$; (c) $S(2 \mathrm{DVD}), S\left(K_{\mathrm{DP}}, Z\right)$, and $S_{\text {et }}(Z)$ (blue, red, and green lines); and (d) snow accumulations measured by 2DVD and estimated via $S\left(K_{\mathrm{DP}}, Z\right)$ and $S_{\text {et }}(Z)$ (blue, red, and green curves), for $25 \mathrm{Feb} 2012$.

IWC, whereas, in the case of the $20 \%$ particles' density increase, the multipliers of the polarimetric relations for $S$ and IWC decrease by $\sim 11 \%$. The exponents of $K_{\mathrm{DP}}$ and $Z$ in $S\left(K_{\mathrm{DP}}, Z\right)$ and $\operatorname{IWC}\left(K_{\mathrm{DP}}, Z\right)$ are almost insensitive to the change in particle density.

Sensitivity of the polarimetric relations for estimation of $S$ and IWC to snowflake shapes, orientations, and degrees of riming (density change) is a primary source of uncertainty in the $S$ and IWC estimations. This uncertainty could be evaluated using radar observations and snow gauge measurements at the surface or aircraft probes in situ. Thus, the suggested polarimetric relations could be "calibrated" experimentally using radar data; this is a subject of ongoing study.

Analysis of $K_{\mathrm{DP}}$ measurements in snow at $\mathrm{S}$ band indicates that $K_{\mathrm{DP}}$ is usually low and noisy in heavily aggregated dry snow and its reliable estimation may require spatial averaging over relatively large areas (Ryzhkov and Zrnić 1998). The situation is better at C and $\mathrm{X}$ bands because $K_{\mathrm{DP}}$ is inversely proportional to the radar wavelength. Because our computations have been performed for $\mathrm{S}$ band $(\lambda=11.08 \mathrm{~cm})$, the corresponding relations at other wavelengths within this band and at shorter wavelengths can be obtained by the wavelength scaling of $K_{\mathrm{DP}}$. The C- and X-band relations might need additional tuning according to the type of snow and reference ground measurements.
The new polarimetric radar processing techniques, such as quasi-vertical profiles (Ryzhkov et al. 2016; Griffin et al. 2018) and enhanced (or "columnar") vertical profiles (Bukovčić et al. 2017) based on azimuthal averaging to reduce the statistical error of the $K_{\mathrm{DP}}$ estimate, can significantly improve the quality of the radar snowfall measurements. Oversampling of the differential phase data at spacing considerably lower than the length of the radar pulse could additionally improve the $K_{\mathrm{DP}}$ accuracy. Another possibility is to capitalize on the $K_{\mathrm{DP}}$ measurements in the DGL aloft in the temperature interval between $-20^{\circ}$ and $-10^{\circ} \mathrm{C}$, where $K_{\mathrm{DP}}$ is significantly higher than at warmer temperatures below the DGL (e.g., Kennedy and Rutledge 2011; Bechini et al. 2013), and make projections down to the surface assuming that the snow rate or ice water content are conserved in the process of aggregation. These options will be explored in future research.

\section{Summary}

Basic principles for polarimetric measurements of snow rate and ice water content are outlined in this study. A combined use of $Z$ and $K_{\mathrm{DP}}$ for quantitative estimation of liquid equivalent snowfall rate $S$ and ice water content IWC is suggested. Analysis of 2Dvideo-disdrometer data from dry snow indicates that the 


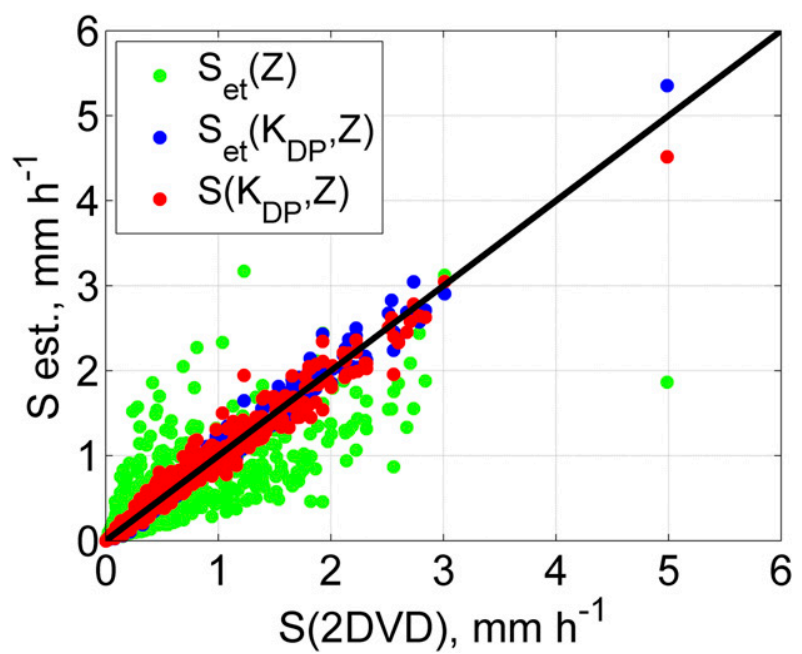

FIG. 13. Scatterplots of $S(2 \mathrm{DVD})$ vs $S_{\mathrm{et}}(Z)$ (green dots), $S(2 \mathrm{DVD})$ vs $S_{\mathrm{et}}\left(K_{\mathrm{DP}}, Z\right)$ (blue dots), and $S(2 \mathrm{DVD})$ vs $S\left(K_{\mathrm{DP}}, Z\right)$ (red dots), for $25 \mathrm{Feb} 2012$. Correlation coefficients between $S(2 \mathrm{DVD})$ and $S_{\mathrm{et}}(Z)$, $S_{\mathrm{et}}\left(K_{\mathrm{DP}}, Z\right)$, and $S\left(K_{\mathrm{DP}}, Z\right)$ are $0.825,0.993$, and 0.988 , respectively.

combination of $Z$ and $K_{\mathrm{DP}}$ dramatically reduces the uncertainty in the estimates of $S$ and IWC caused by the variability of the snow size distribution relative to the traditional $Z$-based estimators.

To derive the $S\left(K_{\mathrm{DP}}, Z\right)$ and $\operatorname{IWC}\left(K_{\mathrm{DP}}, Z\right)$ relations from the $2 \mathrm{D}$ video disdrometer, a problem of particle mismatching is addressed by filtering out the obviously mismatched particles with discriminating thresholds. These thresholds are determined from the (heated) rain gauges or pluvio total event accumulations. To better represent the impact of snow riming, the so-called adjusted snow density (obtained from 2DVD terminal velocity measurements) is used in computations of polarimetric variables and microphysical parameters.

The theoretical relations for parameterization of $S(Z)$ and IWC $(Z)$ by the intercept $N_{0 \mathrm{~s}}$ of the exponential size distribution are verified with the disdrometer measurements. These served as a starting point for the derivation of the $S\left(K_{\mathrm{DP}}, Z\right)$ and $\operatorname{IWC}\left(K_{\mathrm{DP}}, Z\right)$ relations.

It is shown that snow rate $S$ and ice water content IWC can be obtained from the bivariate power-law relations, $S=\gamma_{1} K_{\mathrm{DP}}^{\alpha_{1}} Z^{\beta_{1}}$ [see (27)] and IWC $=\gamma_{2} K_{\mathrm{DP}}^{\alpha_{2}} Z^{\beta_{2}}$ [see (28)], where the multipliers $\gamma_{1}$ and $\gamma_{2}$ depend on the particle shapes, orientations, and degrees of riming (snow density). These multipliers can be determined experimentally by comparing radar data with in situ measurements of $S$ and IWC.

In addition to the polarimetric relations for $S$ and IWC, similar relations for the intercept $N_{0 \mathrm{~s}}$ and slope parameter $\Lambda_{s}$ of the exponential size distribution, $N_{0 \mathrm{~s}}\left(K_{\mathrm{DP}}, Z\right)$ and $\Lambda_{s}\left(K_{\mathrm{DP}}, Z\right)$, are developed. These can

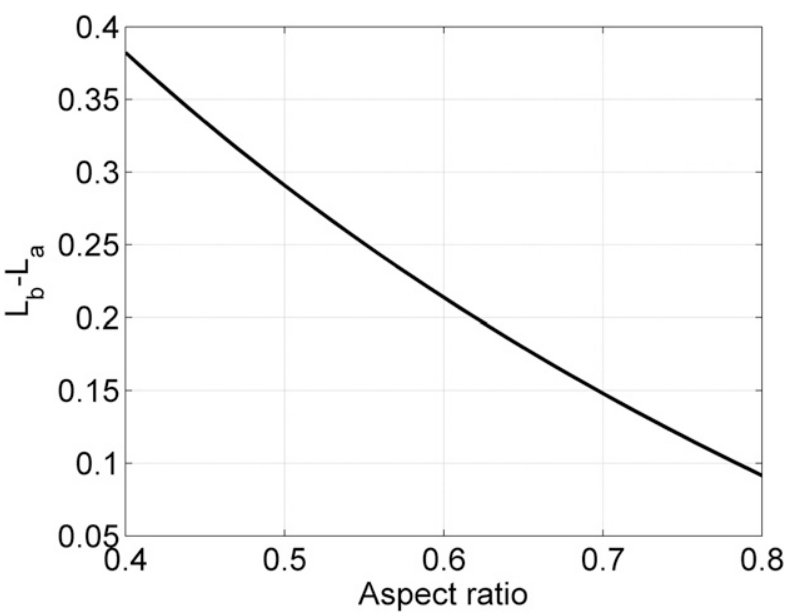

FIG. 14. Dependence of $L_{b}-L_{a}$ on the aspect ratio of oblate spheroids.

be used for direct microphysical retrieval from the polarimetric radar measurements.

Initial $S\left(K_{\mathrm{DP}}, Z\right)$ and $\operatorname{IWC}\left(K_{\mathrm{DP}}, Z\right)$ relations were obtained from the disdrometer analysis of 16 snow events in Oklahoma. In addition to excellent performance locally (Oklahoma), these relations perform reasonably well for snowstorms in Colorado and very well in Canada, two distinct climate regions, which attests to the potentially universal character of such relations.

The correlation coefficient between the measured and estimated $S\left(K_{\mathrm{DP}}, Z\right)$ [or $\operatorname{IWC}\left(K_{\mathrm{DP}}, Z\right)$ ] is much higher $(\sim 0.99)$ than for $S(Z)$ [or $\operatorname{IWC}(Z)$ ] estimates $(\sim 0.8$ to $\sim 0.89$ ), which increases our confidence in the utility of the novel polarimetric relations. Sensitivity tests indicate the exponents of $K_{\mathrm{DP}}$ and $Z$ are almost constant, with very little dependence on the variability in the snow density, aspect ratio, and width of the angular distribution. This simplifies the adjustment of these relations. To improve performance of $S\left(K_{\mathrm{DP}}, Z\right)$ or $\operatorname{IWC}\left(K_{\mathrm{DP}}, Z\right)$ in distinct climate regions such as Colorado, only the multiplier in $S\left(K_{\mathrm{DP}}, Z\right)$ or $\operatorname{IWC}\left(K_{\mathrm{DP}}, Z\right)$ needs to be adjusted according to the local environmental conditions (temperature, humidity, etc.). This is verified by applying relations $S_{\mathrm{CO}}\left(K_{\mathrm{DP}}, Z\right)$ and $\operatorname{IWC}_{\mathrm{CO}}\left(K_{\mathrm{DP}}, Z\right)$ derived from the Colorado dataset to the Oklahoma dataset; the Colorado polarimetric relation multipliers are $\sim 27 \%$ and $4 \%$ higher than their Oklahoma counterparts. Thus, it appears that the derived relations may have fairly wide applicability. This nonetheless needs to be further investigated.

The practicality of the newly obtained polarimetric relations for snow measurements is contingent on the reliable estimate of $K_{\mathrm{DP}}$, which is notoriously noisy in aggregated snow. Such noisiness can be mitigated by the 
use of spatial averaging and utilization of $K_{\mathrm{DP}}$ measurements aloft in the dendritic growth layer centered at the $-15^{\circ} \mathrm{C}$ isotherm, where the magnitude of $K_{\mathrm{DP}}$ is significantly higher than in heavily aggregated snow near the surface or just above the freezing level. The practical aspects and a demonstration involving actual polarimetric radar snow measurements are currently under study.

Acknowledgments. This work was supported by NOAA/Office of Oceanic and Atmospheric Research under NOAA-University of Oklahoma Cooperative Agreement NA11OAR4320072, the U.S. Department of Commerce. Additional funding came from the National Science Foundation (Grants 1143948 and AGS-1046171) and the Department of Energy Grant DE-SC0008811.

\section{APPENDIX}

\section{Theoretical Relations}

The theoretical $S(Z)$ relation is derived following Rasmussen et al. (2003). The magnitude of $S$ is

$$
S=0.6 \times 10^{-3} \pi \int_{0}^{D_{\max }} \frac{\rho_{s}(D)}{\rho_{w}} D^{3} U_{t}^{(s)}(D) N(D) d D,
$$

where $\rho_{w}$ and $\rho_{s}(D)$ are the densities of water and snow $\left(\mathrm{g} \mathrm{cm}^{-3}\right)$, respectively; $U_{t}^{(s)}$ is the terminal velocity of snowflakes $\left(\mathrm{m} \mathrm{s}^{-1}\right) ; N(D)$ is the size distribution of snowflakes $\left(\mathrm{m}^{-3} \mathrm{~mm}^{-1}\right)$; and $D$ is the equivolume diameter $(\mathrm{mm})$. We assume that the density of dry snow decreases with diameter $D$ and degree of riming $f_{\text {rim }}$ as specified by Brandes et al. (2007) and Zawadzki et al. (2005):

$$
\rho_{s}(D)=c_{\rho} f_{\text {rim }} D^{-0.922}\left(\mathrm{~g} \mathrm{~cm}^{-3}\right) .
$$

The $f_{\text {rim }}$ changes from 1 for unrimed snow to 5 for heavily rimed snow. According to Zawadzki et al. (2005, 2010), the terminal velocity of snowflakes can be approximated by

$$
U_{t}^{(s)}=a_{u} f_{\mathrm{rim}}^{1 / 3} D^{0.18}
$$

where $a_{u}$ is a function of the temperature $T_{s}$ at the location of snow and its distance from the cloud-top $H_{\mathrm{st}}$ :

$$
a_{u}=0.73+0.037 H_{\mathrm{st}}+0.011 T_{s} .
$$

In (A3) and (A4), the units for the quantities are: $D$ $(\mathrm{mm}), U_{t}^{(s)}\left(\mathrm{m} \mathrm{s}^{-1}\right), H_{\mathrm{st}}(\mathrm{km})$, and $T_{s}\left({ }^{\circ} \mathrm{C}\right)$.

The theoretical relation between $Z$ and IWC can be derived starting from the equation for

$$
\mathrm{IWC}=\frac{\pi}{6} 10^{-3} \int_{0}^{D_{\max }} \rho_{s}(D) D^{3}(D) N(D) d D .
$$

In (A5), IWC is in grams per meter cubed.

Size distributions of snowflakes can be well approximated by

$$
N(D)=N_{0 \mathrm{~s}} \exp \left(-\Lambda_{\mathrm{s}} D\right)
$$

where the slope $\Lambda_{s}$ usually varies between 1 and $10 \mathrm{~mm}^{-1}$ (e.g., Ryan 2000; Heymsfield et al. 2002). The maximal size of dry snowflakes $D_{\max }$ commonly changes from 1 to $10 \mathrm{~mm}$ and is related to the slope $\Lambda_{s}$ (Heymsfield et al. 2002):

$$
D_{\max }=11.6 \Lambda_{s}^{-0.91},
$$

where $D_{\max }$ is in millimeters and $\Lambda_{s}$ is in inverse millimeters. With such dependence of $D_{\max }$ on $\Lambda_{s}$, integration over the size spectra in (A1) and (A5) between 0 and $\infty$ yields the following expression for $S$ and IWC:

$$
\begin{gathered}
S=3.36 \times 10^{-4} \frac{a_{u} f_{\mathrm{rim}}^{4 / 3} N_{0 \mathrm{~s}}}{\rho_{w}} \int_{0}^{\infty} D^{2.26} \exp \left(-\Lambda_{s} D\right) d D=3.36 \times 10^{-4} \frac{a_{u} f_{\mathrm{rim}}^{4 / 3} N_{0 \mathrm{~s}} \Gamma(3.26)}{\rho_{w} \Lambda_{s}^{3.26}} \text { and } \\
\mathrm{IWC}=9.315 \times 10^{-5} f_{\mathrm{rim}} N_{0 \mathrm{~s}} \int_{0}^{\infty} D^{2.08} \exp \left(-\Lambda_{s} D\right) d D=9.315 \times 10^{-5} \frac{f_{\mathrm{rim}} N_{0 \mathrm{~s}} \Gamma(3.078)}{\Lambda_{s}^{3.078}}
\end{gathered}
$$

These equations simplify to

$$
S=8.65 \times 10^{-4} \frac{a_{u} f_{\text {rim }}^{4 / 3} N_{0 \mathrm{~s}}}{\Lambda_{s}^{3.26}} \text { and }
$$




$$
\mathrm{IWC}=2 \times 10^{-4} \frac{f_{\mathrm{rim}} N_{0 \mathrm{~s}}}{\Lambda_{s}^{3.08}}
$$

Here, $S$ is in millimeters per hour, IWC is in grams per meter cubed, $\Lambda_{s}$ is in inverse millimeters, and $N_{0 \mathrm{~s}}$ is in meters cubed per millimeter.

Following (12) and assuming a spherical shape for the snowflakes (the spheres are used to roughly estimate the exponent and for quick comparison with other relations), the radar reflectivity of dry snow can be expressed by

$$
Z_{s}=\frac{4 \lambda^{4}}{\pi^{4}\left|K_{w}\right|^{2}} \int_{0}^{\infty}\left|s_{a}^{(\pi)}\right|^{2}(D) d D
$$

In the Rayleigh approximation,

$$
s_{a}^{(\pi)}=\frac{\pi^{2} D^{3}}{2 \lambda^{2}} \frac{\varepsilon_{s}-1}{\varepsilon_{s}+2}
$$

where $\varepsilon_{s}$ is the dielectric constant of snow. If snow density is relatively low, then

$$
\frac{\varepsilon_{s}-1}{\varepsilon_{s}+2}=\frac{\rho_{s}(D)}{\rho_{i}} \frac{\varepsilon_{i}-1}{\varepsilon_{i}+2} \text { (Debye formula) }
$$

and the equation for $Z$ can be rewritten as

$$
Z=\frac{\left|K_{i}\right|^{2}}{\left|K_{w}\right|^{2}} \int_{0}^{D_{\max }} \frac{\rho_{s}^{2}(D)}{\rho_{i}^{2}} D^{6} N(D) d D,
$$

where $K_{i}=\left(\varepsilon_{i}-1\right) /\left(\varepsilon_{i}+2\right) ; K_{w}=\left(\varepsilon_{w}-1\right) /\left(\varepsilon_{w}+2\right) ; \varepsilon_{\mathrm{i}}$ and $\varepsilon_{\mathrm{w}}$ are dielectric constants of solid ice and water, respectively; and $\rho_{i}=0.917 \mathrm{~g} \mathrm{~cm}^{-3}$ is the density of solid ice. Using (A2) and (A6) and substituting the upper limit of the integration $D_{\max }$ with infinity (similar to derivation of $S$ ), one obtains

$$
Z=0.219 \frac{f_{\text {rim }}^{2} N_{0 \mathrm{~s}}}{\Lambda_{s}^{5.16}}
$$

In (A16), $Z$ is in millimeters to the sixth power per meter cubed. The $S(Z)$ relation follows from (A10) and (A16) and is

$$
S=2.26 \times 10^{-3} a_{u} f_{\mathrm{rim}}^{0.07} N_{0 \mathrm{~s}}^{0.37} Z^{0.63},
$$

whereas the IWC(Z) is obtained from (A11) and (A16) and it is

$$
\mathrm{IWC}=4.95 \times 10^{-4} f_{\text {rim }}^{-0.19} N_{0 \mathrm{~s}}^{0.4} Z^{0.6} .
$$

It follows from (A17) and (A18) that the coefficients $a_{s}$ and $c_{s}$ in the relations $S=a_{s} Z^{b_{s}}$ and $\mathrm{IWC}=c_{s} Z^{d_{s}}$ are almost entirely dependent on the intercept of the exponential size distribution $N_{0 \mathrm{~s}}$. The coefficient $a_{s}$ is practically insensitive to the degree of snow riming $f_{\text {rim }}$, whereas $c_{s}$ is marginally sensitive to $f_{\text {rim }}$. Indeed, a change of $f_{\text {rim }}$ from 1 to 5 causes only an $11 \%$ increase in $a_{s}$ and a $27 \%$ decrease in $c_{s}$. The inversion of (A17) and (A18), $Z(S)$ and $Z$ (IWC), often used in practical applications can be written as

$$
Z(S)=1.52 \times 10^{4} a_{u}^{-1.58} N_{0 \mathrm{~s}}^{-0.58} S^{1.58}
$$

and

$$
Z(\mathrm{IWC})=686.3 f_{\mathrm{rim}}^{0.32} N_{0 \mathrm{~s}}^{-0.68} \mathrm{IWC}^{1.68} .
$$

Equation (A18) is consistent with the relation between IWC, $Z$, and $N_{0 \mathrm{~s}}$ that was empirically derived by Delanoë et al. (2014) using a very large dataset of in situ aircraft measurements of ice:

$$
\mathrm{IWC}=2.36 \times 10^{-4} N_{0 \mathrm{~s}}^{0.42} Z^{0.58} .
$$

Similar to the radar reflectivity factor, the specific differential phase

$$
K_{\mathrm{DP}}=\frac{0.18 \lambda}{\pi} r \int_{0}^{\infty} \operatorname{Re}\left[s_{a}^{(0)}-s_{b}^{(0)}\right] N(D) d D
$$

in snow can be obtained as a function of the parameters of the snow size distributions $\left(N_{0 s}\right.$ and $\left.\Lambda_{s}\right)$ and the factors characterizing snowflake shapes and orientations. In the Rayleigh approximation,

$s_{a}^{(0)}-s_{b}^{(0)}=\frac{\pi^{2} D^{3}}{6 \lambda^{2}}\left[\frac{\varepsilon_{s}-1}{L_{a}\left(\varepsilon_{s}-1\right)+1}-\frac{\varepsilon_{s}-1}{L_{b}\left(\varepsilon_{s}-1\right)+1}\right]$.

For snow with low density, the magnitude of the dielectric constant of snow, $\varepsilon_{s}$, is very close to 1 and $L_{a, b}\left|\varepsilon_{s}-1\right| \ll 1$; therefore,

$$
\frac{\varepsilon_{s}-1}{L_{a}\left(\varepsilon_{s}-1\right)+1}-\frac{\varepsilon_{s}-1}{L_{b}\left(\varepsilon_{s}-1\right)+1} \approx\left(\varepsilon_{s}-1\right)^{2}\left(L_{b}-L_{a}\right)=9 \frac{\rho_{s}^{2}}{\rho_{i}^{2}}\left(\frac{\varepsilon_{i}-1}{\varepsilon_{i}+2}\right)^{2}\left(L_{b}-L_{a}\right) .
$$


This yields the following equation for $K_{\mathrm{DP}}$ :

$$
K_{\mathrm{DP}}=\frac{0.27 \pi r}{\lambda \rho_{i}^{2}}\left(\frac{\varepsilon_{i}-1}{\varepsilon_{i}+2}\right)^{2} \int_{0}^{\infty}\left(L_{b}-L_{a}\right) \rho_{s}^{2}(D) D^{3} N(D) d D,
$$

which can be further simplified after integration if the exponential size distribution (A6) is assumed:

$$
K_{\mathrm{DP}}=0.192 \frac{c_{\rho}^{2} f_{\text {rim }}^{2} r\left(L_{b}-L_{a}\right) N_{0 \mathrm{~s}}}{\lambda \Lambda_{s}^{2.16}} .
$$

Equation (A26) shows that similarly to $Z, K_{\mathrm{DP}}$ is proportional to the product of $f_{\text {rim }}^{2} \times N_{0 \mathrm{~s}}$ but that it also strongly depends on the shape of the snowflakes represented by the factor $L_{b}-L_{a}$ and the width of the canting angle distribution $\sigma$ through the factor $r=\exp \left(-2 \sigma^{2}\right)$.

As a result of the inverse dependence of snow density on equivolume diameter, the radar reflectivity factor is close to the fourth moment of the snow size distribution whereas the specific differential phase is close to its first moment if snow is aggregated and has low density. Note that for pristine crystals with high density, which do not exhibit strong size dependence, $Z$ is still close to the sixth moment and $K_{\mathrm{DP}}$ to the third moment of the size distributions. In other words, $K_{\mathrm{DP}}$ is directly proportional to the ice water content for pristine and lightly aggregated crystals, as claimed by Vivekanandan et al. (1994) and Ryzhkov et al. (1998).

\section{REFERENCES}

Atlas, D., S. Y. Matrosov, A. J. Heymsfield, M.-D. Chou, and D. B. Wolff, 1995: Radar and radiation properties of ice clouds. J. Appl. Meteor., 34, 2329-2345, doi:10.1175/ 1520-0450(1995)034<2329:RARPOI >2.0.CO;2.

Aydin, K., and C. Tang, 1995: Estimation of ice water content with 94$\mathrm{GHz}$ millimeter wave radar observables. Preprints, 27th Conf. on Radar Meteorology, Vail, CO, Amer. Meteor. Soc., 550-552.

Bechini, R., L. Baldini, and V. Chandrasekar, 2013: Polarimetric radar observations in the ice region of precipitating clouds at C-band and X-band radar frequencies. J. Appl. Meteor. Climatol., 52, 1147-1169, doi:10.1175/JAMC-D-12-055.1.

Brandes, E. A., K. Ikeda, G. Zhang, M. Schonhuber, and R. M. Rasmussen, 2007: A statistical and physical description of hydrometeor distributions in Colorado snowstorms using a video disdrometer. J. Appl. Meteor. Climatol., 46, 634-650, doi:10.1175/JAM2489.1.

Brown, P. R. A., and P. N. Francis, 1995: Improved measurements of ice water content in cirrus using a total-water probe. J. Atmos. Oceanic Technol., 12, 410-414, doi:10.1175/ 1520-0426(1995)012<0410:IMOTIW > 2.0.CO;2.

Bukovčić, P., D. Zrnić, and G. Zhang, 2017: Winter precipitation liquid-ice phase transitions revealed with polarimetric radar and 2DVD observations in central Oklahoma. J. Appl. Meteor. Climatol., 56, 1345-1363, https://doi.org/10.1175/JAMC-D-16-0239.1.
Delanoë, J. M. E., A. J. Heymsfield, A. Protat, A. Bansemer, and R. J. Hogan, 2014: Normalized particle size distribution for remote sensing application. J. Geophys. Res. Atmos., 119, 4204-4227, doi:10.1002/2013JD020700.

Fujiyoshi, Y., T. Endoh, T. Yamada, K. Tsuboki, Y. Tachibana, and G. Wakahama, 1990: Determination of a $Z-R$ relationship for snowfall using a radar and high sensitivity snow gauges. J. Appl. Meteor., 29, 147-152, doi:10.1175/ 1520-0450(1990)029<0147:DOARFS $>2.0$.CO;2.

Garrett, T. J., S. E. Yuter, C. Fallgatter, K. Shkurko, S. R. Rhodes, and J. L. Endries, 2015: Orientations and aspect ratios of falling snow. Geophys. Res. Lett., 42, 4617-4622, doi:10.1002/2015GL064040.

Griffin, E., T. Schuur, and A. Ryzhkov, 2018: A polarimetric analysis of ice microphysical processes in snow, using quasivertical profiles. J. Appl. Meteor. Climatol., 57, 31-50, doi:10.1175/JAMC-D-17-0033.1.

Gunn, K. L. S., and J. S. Marshall, 1958: The distribution with size of aggregate snowflakes. J. Meteor., 15, 452-461, doi:10.1175/ 1520-0469(1958)015<0452:TDWSOA > 2.0.CO;2.

Hanesch, M., 1999: Fall velocity and shape of snowflakes. Ph.D. thesis, Swiss Federal Institute of Technology, Zurich, Switzerland, 123 pp., http://e-collection.library.ethz.ch/eserv/eth: 23207/eth-23207-02.pdf.

Hendry, A., Y. Antar, and G. McCormick, 1987: On the relationship between the degree of preferred orientation in precipitation and dual-polarization radar echo characteristics. Radio Sci., 22, 37-50, doi:10.1029/RS022i001p00037.

Heymsfield, A., 1977: Precipitation development in stratiform ice clouds: A microphysical and dynamical study. J. Atmos. Sci., 34, 367-381, doi:10.1175/1520-0469(1977)034<0367:PDISIC > 2.0.CO;2.

_- A. Bansemer, P. Field, S. Durden, J. Stith, J. Dye, W. Hall, and C. Grainger, 2002: Observations and parametrizations of particle size distributions in deep tropical cirrus and stratiform precipitating clouds: Results from in situ observations in TRMM field campaigns. J. Atmos. Sci., 59, 3457-3490, doi:10.1175/1520-0469(2002)059<3457:OAPOPS >2.0.CO;2.

_ S. Matrosov, and N. Wood, 2016: Toward improving ice water content and snow-rate retrievals from radars. Part I: X and W bands, emphasizing CloudSat. J. Appl. Meteor. Climatol., 55, 2063-2090, doi:10.1175/JAMC-D-15-0290.1.

Hogan, R. J., M. P. Mittermaier, and A. J. Illingworth, 2006: The retrievals of ice water content from radar reflectivity factor and temperature and its use in evaluating a mesoscale model. J. Appl. Meteor. Climatol., 45, 301-317, doi:10.1175/ JAM2340.1.

— L. Tian, P. R. A. Brown, C. D. Westbrook, A. J. Heymsfield, and J. D. Eastment, 2012: Radar scattering from ice aggregates using the horizontally aligned oblate spheroid approximation. J. Appl. Meteor. Climatol., 51, 655-671, doi:10.1175/ JAMC-D-11-074.1.

Huang, G.-J., V. N. Bringi, R. Cifelli, D. Hudak, and W. A. Petersen, 2010: A methodology to derive radar reflectivityliquid equivalent snow rate relations using C-band radar and a 2D video disdrometer. J. Atmos. Oceanic Technol., 27, 637651, doi:10.1175/2009JTECHA1284.1.

,,- D. Moisseev, W. A. Petersen, L. Bliven, and D. Hudak, 2015: Use of 2D-video disdrometer to derive mean densitysize and $Z_{e}-\mathrm{SR}$ relations: Four snow cases from the light precipitation validation experiment. Atmos. Res., 153, 34-48, doi:10.1016/j.atmosres.2014.07.013.

Kennedy, P., and S. Rutledge, 2011: S-band dual-polarization radar observations of winter storms. J. Appl. Meteor. Climatol., 50, 844-858, doi:10.1175/2010JAMC2558.1. 
Koistinen, Y., D. Michelson, H. Hohti, and M. Peura, 2003: Operational measurement of precipitation in cold climates. Weather Radar, Principles and Advanced Applications, P. Meischner, Ed., Springer, 78-114.

Korolev, A., and G. Isaac, 2003: Roundness and aspect ratio of particles in ice clouds. J. Atmos. Sci., 60, 1795-1808, https://doi.org/ 10.1175/1520-0469(2003)060<1795:RAAROP $>2.0 . C O ; 2$.

,$- \ldots$, and J. Hallett, 2000: Ice particle habits in stratiform clouds. Quart. J. Roy. Meteor. Soc., 126, 2873-2902, doi:10.1002/qj.49712656913.

Kruger, A., and W. F. Krajewski, 2002: Two-dimensional video disdrometer: A description. J. Atmos. Oceanic Technol., 19, 602-617, doi:10.1175/1520-0426(2002)019<0602: TDVDAD $>2.0 . \mathrm{CO} ; 2$.

Liu, C. L., and A. J. Illingworth, 2000: Toward more accurate retrievals of ice water content from radar measurements of clouds. J. Appl. Meteor., 39, 1130-1146, doi:10.1175/ 1520-0450(2000)039<1130:TMAROI $>2.0 . \mathrm{CO} ; 2$.

Matrosov, S., 1997: Variability of microphysical parameters in high-altitude ice clouds: Results of the remote sensing method. J. Appl. Meteor., 36, 633-648, doi:10.1175/1520-0450-36.6.633.

_, 2007: Modeling backscatter properties of snowfall at millimeter wavelengths. J. Atmos. Sci., 64, 1727-1736, doi:10.1175/JAS3904.1.

, R. Reinking, and I. Djalalova, 2005: Inferring fall attitudes of pristine dendritic crystals from polarimetric radar data. J. Atmos. Sci., 62, 241-250, doi:10.1175/JAS-3356.1.

_ C. Campbell, D. Kingsmill, and E. Sukovich, 2009: Assessing snowfall rates from X-band radar reflectivity measurements. J. Atmos. Oceanic Technol., 26, 2324-2339, doi:10.1175/ 2009JTECHA1238.1.

Melnikov, V., and J. Straka, 2013: Axis ratios and flutter angles of cloud ice particles: Retrievals from radar data. J. Atmos. Oceanic Technol., 30, 1691-1703, doi:10.1175/ JTECH-D-12-00212.1.

Mitchell, D. L., R. Zhang, and R. L. Pitter, 1990: Mass-dimensional relationships for ice particles and the influence of riming on snowfall rates. J. Appl. Meteor., 29, 153-163, doi:10.1175/ 1520-0450(1990)029<0153:MDRFIP>2.0.CO;2.

Ohtake, T., and T. Henmi, 1970: Radar reflectivity of aggregated snowflakes. Preprints, 14th Conf. on Radar Meteorology, Tucson, AZ, Amer. Meteor. Soc., 209-210.

Puhakka, T., 1975: On the dependence of the Z-R relation on the temperature in snowfall. Preprints, 16th Conf. on Radar Meteorology, Houston, TX, Amer. Meteor. Soc., 504-507.

Rasmussen, R., M. Dixon, S. Vasiloff, F. Hage, S. Knight, J. Vivekanandan, and M. Xu, 2003: Snow nowcasting using a real-time correlation of radar reflectivity with snow gauge accumulation. J. Appl. Meteor., 42, 20-36, doi:10.1175/ 1520-0450(2003)042<0020:SNUART $>2.0$. CO; 2 .

Ryan, B., 2000: A bulk parametrization of the ice particle size distribution and the optical properties in ice clouds. J. Atmos. Sci., 57, 1436-1451, doi:10.1175/1520-0469(2000)057<1436: ABPOTI $>2.0 . \mathrm{CO} ; 2$.

Ryzhkov, A., and D. Zrnić, 1998: Discrimination between rain and snow with a polarimetric radar. J. Appl. Meteor., 37, 1228-1240, doi:10.1175/1520-0450(1998)037<1228: DBRASW $>2.0 . \mathrm{CO} ; 2$.

,$- \ldots$, and B. A. Gordon, 1998: Polarimetric method for ice water content determination. J. Appl. Meteor., 37, 125-134, doi:10.1175/1520-0450(1998)037<0125:PMFIWC>2.0.CO;2.

- M. Pinsky, A. Pokrovsky, and A. Khain, 2011: Polarimetric radar observation operator for a cloud model with spectral microphysics. J. Appl. Meteor. Climatol., 50, 873-894, doi:10.1175/2010JAMC2363.1.

P. Zhang, H. Reeves, M. Kumjian, T. Tschallener, S. Troemel, and C. Simmer, 2016: Quasi-vertical profiles-A new way to look at polarimetric radar data. J. Atmos. Oceanic Technol., 33, 551-562, doi:10.1175/JTECH-D-15-0020.1.

Sassen, K., 1987: Ice cloud content from radar reflectivity. J. Climate Appl. Meteor., 26, 1050-1053, doi:10.1175/ 1520-0450(1987)026<1050:ICCFRR > 2.0.CO;2.

Schönhuber, M., G. Lammer, and W. L. Randeu, 2008: The 2Dvideo-disdrometer. Precipitation: Advances in Measurement, Estimation and Prediction, S. Michaelides, Ed., Springer, 3-31.

Sekhon, R. S., and R. C. Srivastava, 1970: Snow size spectra and radar reflectivity. J. Atmos. Sci., 27, 299-307, doi:10.1175/ 1520-0469(1970)027<0299:SSSARR>2.0.CO;2.

Skofronick-Jackson, G., and Coauthors, 2015: Global Precipitation Measurement Cold Season Precipitation Experiment (GCPEX). Bull. Amer. Meteor. Soc., 96, 1719-1741, doi:10.1175/BAMS-D-13-00262.1.

Stephens, G. L., S. C. Tsay, J. P. W. Stackhouse, and P. Flatau, 1990: The relevance of the microphysical and radiative properties of cirrus clouds to climate and climatic feedback. J. Atmos. Sci., 47, 1742-1753, doi:10.1175/ 1520-0469(1990)047<1742:TROTMA > 2.0.CO;2.

Szyrmer, W., and I. Zawadzki, 2010: Snow studies. Part II: Average relationship between mass of snowflakes and their terminal fall velocity. J. Atmos. Sci., 67, 3319-3335, doi:10.1175/ 2010JAS3390.1.

Tiira, J., D. N. Moisseev, A. Von Lerber, D. Ori, A. Tokay, L. F. Bliven, and W. Petersen, 2016: Ensemble mean density and its connection to other microphysical properties of falling snow as observed in southern Finland. Atmos. Meas. Tech., 9, 4825-4841, doi:10.5194/amt-9-4825-2016.

van de Hulst, H., 1981: Light Scattering by Small Particles. Dover, $470 \mathrm{pp}$.

Vasiloff, S.V., 1997: Interpretation of radar data during snow events in mountainous terrain. Western Region Tech. Attachment 97-35, 16 pp., https://www.weather.gov/media/wrh/ online_publications/TAs/ta9735.pdf.

Vivekanandan, J., V. N. Bringi, M. Hagen, and P. Meischner, 1994: Polarimetric radar studies of atmospheric ice particles. IEEE Trans. Geosci. Remote Sens., 32, 1-10, doi:10.1109/36.285183.

Wolfe, J. P., and J. R. Snider, 2012: A relationship between reflectivity and snow rate for a high-altitude S-band radar. J. Appl. Meteor. Climatol., 51, 1111-1128, doi:10.1175/ JAMC-D-11-0112.1.

— between reflectivity and snow rate for a high-altitude S-band radar."' J. Appl. Meteor. Climatol., 52, 730-731, doi:10.1175/ JAMC-D-12-0277.1.

Zawadzki, I., W. Szyrmer, C. Bell, and F. Fabry, 2005: Modeling of the melting layer. Part III: The density effect. J. Atmos. Sci., 62, 3705-3723, doi:10.1175/JAS3563.1.

_ natural variability of snow terminal velocity. J. Atmos. Sci., 67, 1591-1604, doi:10.1175/2010JAS3342.1.

Zhang, G., 2016: Weather Radar Polarimetry. CRC Press, 304 pp.

- S. Luchs, A. Ryzhkov, M. Xue, L. Ryzhkova, and Q. Cao, 2011: Winter precipitation microphysics characterized by polarimetric radar and video disdrometer observations in central Oklahoma. J. Appl. Meteor. Climatol., 50, 1558-1570, doi:10.1175/2011JAMC2343.1. 